\title{
Zircônia parcialmente estabilizada de baixo custo produzida por meio de mistura de pós com aditivos do sistema $\mathrm{MgO}-\mathrm{Y}_{2} \mathrm{O}_{3}-\mathrm{CaO}$
}

\section{(Low cost partially-stabilized zirconia ceramic produced by powder mixing with additives of $\mathrm{MgO}-\mathrm{Y}_{2} \mathrm{O}_{3}$-CaO system)}

\author{
H. N. Yoshimura', A. L. Molisani ${ }^{1}$, N. E. Narita ${ }^{1}$, M. P. Gonçalves ${ }^{2}$ M. F. de Campos ${ }^{3}$ \\ ${ }^{1}$ Instituto de Pesquisas Tecnológicas do Estado de S. Paulo S.A. - IPT \\ Av. Prof. Almeida Prado 532, S. Paulo, SP 05508-901 \\ ${ }^{2}$ Engecer Ltda., R. Nossa Sra. Auxiliadora 1141, S. Carlos, SP \\ ${ }^{3}$ Instituto Nacional de Metrologia, Normalização e Qualidade Industrial - INMETRO \\ Av. Nossa Senhora das Graças 50, Xerém, Duque de Caxias, RJ 25250-020.
}

\begin{abstract}
Resumo
Verificou-se a possibilidade de se produzir cerâmica de zircônia parcialmente estabilizada (PSZ) utilizando um pó de zircônia monoclínica comercial com a adição de $\mathrm{MgO}, \mathrm{Y}_{2} \mathrm{O}_{3}$ e/ou $\mathrm{CaO}$ por meio de mistura mecânica de pós. A metodologia adotada visou primordialmente diminuir o custo da matéria-prima. Foram preparadas amostras de PSZ na forma de cilindros com adições individuais e com misturas de aditivos em sinterizações entre 1500 e $1700{ }^{\circ} \mathrm{C}$ no campo binário tetragonal-cúbica. As amostras foram usinadas em retificadora cilíndrica e submetidas ao ensaio de rugosidade. Também foram determinadas as fases presentes (difração de raios X, método de Rietveld), a microestrutura (microscopia eletrônica de varredura), a densidade/porosidade, a dureza Vickers, a tenacidade à fratura e a resistência à flexão biaxial. Em geral, a melhor temperatura de sinterização foi $1500{ }^{\circ} \mathrm{C}$. As melhores composições foram uma com adição simples de $\mathrm{MgO}$ e três composições mistas contendo $\mathrm{Y}_{2} \mathrm{O}_{3}$. As características destas amostras sinterizadas a $1500{ }^{\circ} \mathrm{C}$ foram próximas às de um pó comercial pré-aditivado com $\mathrm{MgO}$ (Mg-PSZ) sinterizado a $1700{ }^{\circ} \mathrm{C}$. Palavras-chave: zircônia, aditivo, processamento, propriedades mecânicas, sinterização.
\end{abstract}

\begin{abstract}
The feasibility of producing partially stabilized zirconia (PSZ) ceramics using a commercial monoclinic zirconia powder with the addition of $\mathrm{MgO}, \mathrm{Y}_{2} \mathrm{O}_{3}$, and/or $\mathrm{CaO}$ by powder mixing route was studied. The adopted methodology aimed mainly to lower the raw-material cost. PSZ samples with cylindrical shape with single and mixed additions were prepared by sintering between 1500 and $1700^{\circ} \mathrm{C}$ in the tetragonal-cubic two-phase region. The samples were ground in a centerless grinding machine and the surface roughness was measured. Crystalline phases (X-ray diffraction, Rietveld method), microstructure (scanning electron microscopy), density/porosity, Vickers hardness, fracture toughness, and biaxial flexural strength of the sintered samples were measured. In general, the best sintering temperature was $1500^{\circ} \mathrm{C}$. The best additive compositions were one with single addition of $\mathrm{MgO}$ and three with mixed additions containing $\mathrm{Y}_{2} \mathrm{O}_{3}$. The results of these samples sintered at $1500^{\circ} \mathrm{C}$ were close to the results of a commercial $M g$-PSZ sintered at $1700^{\circ} \mathrm{C}$.
\end{abstract}

Keywords: zirconia, additive, processing, mechanical properties, sintering.

\section{INTRODUÇÃO}

Cerâmicas de zircônia $\left(\mathrm{ZrO}_{2}\right)$ apresentam elevada resistência química e refratariedade e podem apresentar elevadas propriedades mecânicas e condutividade iônica. Em decorrência, têm sido aplicadas nas indústrias química, petroquímica, metalúrgica e mecânica. Algumas aplicações como elementos estruturais incluem: componentes de bombas e válvulas mecânicas, cutelaria, matrizes de conformação de metais, próteses ortopédicas e dentárias (biomaterial) e refratários. Também podem ser utilizadas como eletrólitos sólidos em sensores de oxigênio, baterias e células a combustível $[1,2]$.

A zircônia pura apresenta três fases: monoclínica, estável até cerca de $1170{ }^{\circ} \mathrm{C}$; tetragonal de 1170 até $2370{ }^{\circ} \mathrm{C}$; e cúbica de $2370^{\circ} \mathrm{C}$ até a temperatura de fusão $\left(2680^{\circ} \mathrm{C}\right)$. No resfriamento, a fase tetragonal transforma-se na fase monoclínica por meio de transformação martensítica acompanhada por uma grande variação de volume (3 a 5\%), que é suficiente para fraturar um corpo sinterizado. Assim, corpos sinterizados de cerâmicas de zircônia são produzidos com aditivos que estabilizam as fases de alta temperatura (tetragonal e cúbica). Os principais tipos de cerâmicas de zircônia são: zircônia tetragonal policristalina (TZP), zircônia totalmente estabilizada (FSZ, 
geralmente fase cúbica) e zircônia parcialmente estabilizada (PSZ), que pode conter duas ou três fases polimórficas [1-3]. Os principais aditivos estabilizadores utilizados na zircônia são $\mathrm{MgO}, \mathrm{Y}_{2} \mathrm{O}_{3}$ e $\mathrm{CaO}$, mas outros também podem ser utilizados isoladamente ou em conjunto com outros aditivos, como $\mathrm{CeO}_{2}, \mathrm{Nd}_{2} \mathrm{O}_{3}, \mathrm{ZnO}, \mathrm{CuO}$ e $\mathrm{LaB}_{6}$ [4-7].

A cerâmica de zircônia totalmente estabilizada na forma cúbica geralmente é aplicada como eletrólito sólido. A cerâmica de zircônia tetragonal policristalina estabilizada com ítria (Y-TZP) é sinterizada ao redor de $1500^{\circ} \mathrm{C}$ e apresenta tamanho de grão fino (da ordem de alguns micrômetros) e baixíssima porosidade, o que resulta em elevada resistência à flexão (até $\sim 1 \mathrm{GPa})$, tenacidade à fratura $\left(\sim 10 \mathrm{MPa} \cdot \mathrm{m}^{1 / 2}\right)$, dureza ( 14 GPa) e resistência ao desgaste erosivo. Cerâmicas de Y-TZP são usadas em aplicações sujeitas a altas tensões mecânicas, como em componentes de bombas mecânicas e matrizes para conformação de metais, em aplicações que necessitam alta confiabilidade mecânica, como em próteses ortopédicas, e em aplicações que necessitam de retenção do fio de corte, como em lâminas domésticas (facas e tesouras) e lâminas industriais (para indústria de papel, medicina e corte de fibras de kevlar) [2]. As cerâmicas Y-TZP, entretanto, podem apresentar degradação catastrófica em atmosferas secas e úmidas na faixa de temperatura entre 65 e $500{ }^{\circ} \mathrm{C}$ devido à desestabilização da fase tetragonal para monoclínica [8]. Recentemente, a aplicabilidade da cerâmica Y-TZP como biomaterial tem sido questionada, depois da constatação de que próteses com cabeças de fêmur deste material apresentaram $\sim 400$ casos de falha em curto período no ano de 2001, provavelmente devido ao processo de desestabilização (envelhecimento) a baixa temperatura $\left(37^{\circ} \mathrm{C}\right.$, temperatura do fluido corpóreo) [9].

Zircônia parcialmente estabilizada com MgO (Mg-PSZ) com finos precipitados coerentes de zircônia tetragonal em uma matriz de zircônia cúbica pode ser preparada por meio de sinterização em altas temperaturas no campo da fase cúbica (entre 1650 e $1850{ }^{\circ} \mathrm{C}$ para adições de 8 a 10\% em mol de MgO), seguida de resfriamento relativamente rápido e tratamento térmico posterior para a precipitação controlada da fase tetragonal entre 1100 e $1450{ }^{\circ} \mathrm{C}[2,10]$. Devido à elevada temperatura de sinterização, o tamanho de grão da fase cúbica alcança valores entre cerca de 50 e $100 \mu \mathrm{m}$. Mg-PSZ com 2,8 a 5,0\% em peso de MgO com finas partículas inibidoras de crescimento de grão, por ex., de alumina, pode ser preparada com elevada resistência mecânica [11]. Os precipitados coerentes da fase tetragonal podem alcançar até cerca de um terço do volume do material e o controle do tamanho das partículas é fundamental para a otimização das propriedades mecânicas (tenacidade à fratura e resistência mecânica), pois se forem muito pequenas não se transformam na fase monoclínica sob o campo de tensão da ponta da trinca e se forem muito grandes transformamse espontaneamente durante o resfriamento. Os precipitados apresentam forma lenticular e o comprimento ideal está entre 0,2 e 0,4 $\mu \mathrm{m}$ [12]. As cerâmicas Mg-PSZ apresentam boa estabilidade térmica até temperaturas de cerca de $800{ }^{\circ} \mathrm{C}$. Embora apresentem menores valores de resistência à flexão do que a cerâmica Y-TZP, as cerâmicas Mg-PSZ apresentam maiores resistências ao choque térmico [2]. Assim como as cerâmicas Y-TZP, as cerâmicas Mg-PSZ têm sido aplicadas com sucesso nas indústrias petroquímicas e de processo em geral, como válvulas, assentos, bicos, etc. [2]. Zircônia parcialmente estabilizada, geralmente com ítria, tem sido usada para revestimentos de barreiras térmicas (TBCs) para isolamento térmico de componentes de motores. A aplicação do revestimento sobre um substrato metálico geralmente é realizada pelo processo de spray por plasma [13, 14].

Os elevados valores de resistência à flexão e tenacidade à fratura, $\mathrm{K}_{\mathrm{Ic}}$, das cerâmicas Y-TZP e Mg-PSZ devem-se principalmente à atuação do mecanismo de tenacificação por transformação martensítica da fase tetragonal para monoclínica induzida pelo campo de tensão na ponta da trinca. A expansão volumétrica associada à transformação causa a formação de um campo de tensão de compressão ao redor da trinca (zona de transformação ou de "processamento") que dificulta a sua propagação. Com o crescimento da trinca, aumentam o volume (comprimento) da zona de processamento e a magnitude da tensão de compressão que atua na cauda (wake) da trinca, o que causa aumento da resistência à propagação da trinca (tenacidade). Após certa extensão da trinca, a tenacidade alcança valor máximo e tende a estabilizar formando um platô. Este fenômeno de aumento da tenacidade com o aumento do comprimento da trinca é denominado de comportamento de resistência da trinca ou curva $\mathrm{R}$, e tem sido observado em cerâmicas TZP e PSZ [15]. Uma compilação de dados de $\mathrm{K}_{\mathrm{Ic}}$ reportados em literatura de cerâmicas Y-TZP com 1,5 a $4 \%$ em mol de $\mathrm{Y}_{2} \mathrm{O}_{3}$ mostra valores variando entre 2,5 a 17,2 $\mathrm{MPa} \cdot \mathrm{m}^{1 / 2}$. A grande variação de resultados decorre principalmente do pó de $\mathrm{ZrO}_{2}$ de partida, dos parâmetros de sinterização, de variáveis microestruturais, como tamanho e forma do grão, fase secundária no contorno de grão, teor e distribuição de $\mathrm{Y}_{2} \mathrm{O}_{3}$ e do método de medição [16]. O valor da tenacidade à fratura de materiais que apresentam curva $\mathrm{R}$ pode ser menor em métodos com pré-trincas curtas, como SCF (surface crack in flexure) e IF (indentation fracture), do que em técnicas com pré-trincas longas, como SEPB (single edge precracked beam) e SEVNB (single edge Vnotched beam) [17]. No caso do método IF, a equação para o cálculo do valor de $\mathrm{K}_{\mathrm{Ic}}$ depende da forma da trinca radial gerada na indentação Vickers, que pode ser do tipo mediana ou Palmqvist. No caso das cerâmicas de zircônia, têm sido empregadas tanto equações para trinca mediana [18, 19] como Palmqvist [20-23], entretanto, geralmente, sem comprovação do tipo de trinca gerado. Em decorrência desta dificuldade, há trabalhos que utilizam equações "universais" [24], que independem do tipo de trinca radial gerado.

O comportamento mecânico das cerâmicas Mg-PSZ é complexo, pois depende fortemente da microestrutura, que por sua vez depende das variáveis de processo e do tratamento térmico posterior à sinterização. Hannink et al. [25] observaram em amostras de PSZ com 3,4\% em peso de $\mathrm{MgO}$ que a tenacidade à fratura aumenta e a forma da curva R varia em função do tratamento a $1100{ }^{\circ} \mathrm{C}$. Inferiram 
que a precipitação da fase $\delta\left(\mathrm{Mg}_{2} \mathrm{Zr}_{5} \mathrm{O}_{12}\right)$ diminui a tensão para indução da transformação da fase tetragonal para monoclínica e aumenta o tamanho da zona de transformação. Hughan e Hannink [26] estudaram uma PSZ com 9,7\% em mol (3,4\% em peso) de $\mathrm{MgO}$ e 0,28\% de SrO sinterizada a $1700{ }^{\circ} \mathrm{C}$, onde foram realizados tratamentos isotérmicos entre 1250 e $1500^{\circ} \mathrm{C}$ durante o estágio de resfriamento no ciclo de sinterização. Os resultados de resistência à flexão variaram entre 310 e $648 \mathrm{MPa}$, dependendo do tempo e da temperatura do tratamento isotérmico (na curva de resfriamento da sinterização) e do tratamento térmico a $1100{ }^{\circ} \mathrm{C}$ posterior à sinterização. Zhang et al. [27] prepararam uma cerâmica (Y,Mg)-PSZ com dispersão de partículas de espinélio $\left(\mathrm{MgAl}_{2} \mathrm{O}_{4}\right)$, que foram formadas in situ durante a sinterização a $1700{ }^{\circ} \mathrm{C}$ e restringiram o crescimento de grão da fase cúbica. Partiram de uma mistura de pós com composição de 1,72\% $\mathrm{Y}_{2} \mathrm{O}_{3}-13,76 \%$ $\mathrm{MgO}-84,52 \% \mathrm{ZrO}_{2}$ e adição de 5,90\% $\alpha-\mathrm{Al}_{2} \mathrm{O}_{3}-\mathrm{MgO}$ (porcentagens em mol). O material na condição como sinterizada (zircônia cúbica) apresentou resistência à flexão de $\sim 280 \mathrm{MPa}$ e tenacidade à fratura de $\sim 2,5 \mathrm{MPa} \cdot \mathrm{m}^{1 / 2}$. Após $800 \mathrm{~h}$ de tratamento a $1100{ }^{\circ} \mathrm{C}$ o material alcançou valores de resistência de $640 \mathrm{MPa}$ e tenacidade de 14,14 MPa.m ${ }^{1 / 2}$. Observaram que o tratamento térmico causou a formação das fases zircônia tetragonal, monoclínica e fase $\mathrm{MgO}$, tendo sido quantificado apenas a fração da fase monoclínica que, após 800 h de tratamento, foi de $11 \%$. Os aumentos das propriedades mecânicas foram atribuídos à formação da fase tetragonal "transformável” [27]. Ramaswamy et al. [28] prepararam cerâmicas (Mg-Ti)-PSZ com 10\% em mol de $\mathrm{MgO}$ e 4 e 6\% em mol de $\mathrm{TiO}_{2}$, além da amostra de controle sem $\mathrm{TiO}_{2}$, por meio de mistura de pós e sinterização a 1500 , 1650 e $1700{ }^{\circ} \mathrm{C}$, com tratamento térmico subseqüente a $1150{ }^{\circ} \mathrm{C}$ por $25 \mathrm{~h}$. As fases observadas por difração de raios $\mathrm{X}$ foram zircônia cúbica e monoclínica, sendo que a fração de monoclínica aumentou com o aumento de $\mathrm{TiO}_{2}$, indicando que este óxido desestabiliza a fase cúbica. Em ensaio de choque térmico, o desempenho da amostra sem $\mathrm{TiO}_{2}$ melhorou com o aumento da temperatura de sinterização, enquanto as amostras com $\mathrm{TiO}_{2}$ apresentaram comportamento oposto. Entretanto, as amostras com $\mathrm{TiO}_{2}$ sinterizadas a $1500{ }^{\circ} \mathrm{C}$ apresentaram desempenho superior à amostra sem $\mathrm{TiO}_{2}$ sinterizada a $1700^{\circ} \mathrm{C}$, devido ao crescimento de uma fase alongada rica em Ti durante os ciclos de choque térmico, que reforçou o material e aumentou a resistência ao choque térmico. A amostra com $6 \%$ em mol de $\mathrm{TiO}_{2}$ sinterizada a $1650{ }^{\circ} \mathrm{C}$ apresentou, após ensaio de choque térmico, retenção de cerca de $70 \%$ da resistência à flexão na condição envelhecida a $1150{ }^{\circ} \mathrm{C}$, que foi de $\sim 140 \mathrm{MPa}$. A amostra sem $\mathrm{TiO}_{2}$ sinterizada a $1650{ }^{\circ} \mathrm{C}$ e envelhecida a $1150{ }^{\circ} \mathrm{C}$ apresentou resistência à flexão de $\sim 110 \mathrm{MPa}$. Os autores justificaram que os baixos valores de resistência à flexão foram decorrentes das grandes dimensões dos corposde-prova utilizados (75 x 25 x $7 \mathrm{~mm}$ ) [28]. As cerâmicas PSZ com adição de um único aditivo, principalmente MgO seguido de $\mathrm{CaO}$ e $\mathrm{Y}_{2} \mathrm{O}_{3}$, foram extensivamente investigadas [29]. Há poucos relatos na literatura, entretanto, de cerâmicas
PSZ com sistemas multicomponentes de aditivos [27].

Muitos trabalhos de zircônia apresentam quantificação da fase monoclínica, entretanto poucos apresentam quantificação das fases cúbica e tetragonal devido, principalmente, aos seus padrões de difração serem muito próximos. As quantificações de fases em cerâmicas $\mathrm{Mg}$ PSZ têm sido realizadas pelo método de Rietveld. Hannink et al. [25] analisaram uma PSZ comercial com 3,4\% em peso (9,8\% em mol) de $\mathrm{MgO}$ por difração de nêutrons na condição como sinterizada e determinaram as seguintes fases: $55,1 \%$ de cúbica, $42,3 \%$ de tetragonal e $2,6 \%$ de monoclínica. As condições de sinterização não foram informadas. Submeteram o material ao tratamento térmico a $1100{ }^{\circ} \mathrm{C}$ por 1,2 e $8 \mathrm{~h}$ e observaram que o aumento do tempo de tratamento causou aumento da fração da fase tetragonal, formação e aumento da fase $\delta\left(\mathrm{Mg}_{2} \mathrm{Zr}_{5} \mathrm{O}_{12}\right)$ e diminuição da fase cúbica. Em 8 h de tratamento observaram diminuição da fase tetragonal que foi atribuída à transformação para as fases monoclínica e ortorrômbica durante o resfriamento [25]. Hill e Reichert [30] analisaram amostras comerciais de PSZ com 3,4\% em peso de $\mathrm{MgO}$ e 0,28\% em mol de $\mathrm{SrO}$ na condição como sinterizada (AF) e nos graus comerciais de máxima resistência (MS) e choque térmico (TS) por difração de raios $\mathrm{X}$. Os históricos térmicos das amostras não eram conhecidos, mas os autores acreditam que as amostras foram sinterizadas no campo da fase cúbica a $\sim 1700^{\circ} \mathrm{C}$, resfriadas de forma controlada até a temperatura ambiente e, então (para as amostras MS e TS), submetidas a tratamento térmico sub-eutetóide a $1100^{\circ} \mathrm{C}$. Determinaram as seguintes fases: $47 \%$ de cúbica, $47 \%$ de tetragonal, $2 \%$ de monoclínica e $4 \%$ de ortorrômbica, na amostra AF; $20 \%$ de cúbica, $52 \%$ de tetragonal, $8 \%$ de monoclínica, $7 \%$ de ortorrômbica e $13 \%$ de fase $\delta$, na amostra MS; e $11 \%$ de cúbica, $42 \%$ de tetragonal, $16 \%$ de monoclínica, $15 \%$ de ortorrômbica e $18 \%$ de fase $\delta$, na amostra TS. Cumbrera et al. [31], por sua vez, analisaram por difração de raios X uma cerâmica PSZ comercial com 9\% em mol de MgO, sem mencionar qualquer informação relativa ao histórico térmico da amostra, e determinaram as seguintes fases: $\sim 29 \%$ de cúbica, $\sim 52 \%$ de tetragonal e $\sim 19 \%$ de monoclínica. A falta de informações relativas aos históricos térmicos das amostras de PSZ comerciais analisadas dificulta a análise comparativa entre os diferentes resultados apresentados na literatura. Pelos resultados acima, aparentemente a cerâmica PSZ com $\sim 10 \%$ em mol de $\mathrm{MgO}$ apresenta, após sinterização a $\sim 1700{ }^{\circ} \mathrm{C}, \sim 50 \%$ de fase cúbica, $\sim 45 \%$ de tetragonal e fração residual de monoclínica. O tratamento térmico posterior resulta em diminuição da fase cúbica e aumento das fases monoclínica e, possivelmente, ortorrômbica e fase $\delta$. A fração de tetragonal pode aumentar ou diminuir dependendo das condições do tratamento térmico. Aparentemente não há relatos na literatura sobre quantificação de fases em cerâmicas PSZ com sistemas multicomponentes de aditivos.

No Brasil, as aplicações de cerâmicas de zircônia se justificam pela excelente qualidade da superfície retificada e boa tenacidade à fratura, quando comparadas às cerâmicas 
de alumina. Peças comumente fabricadas em Y-TZP são anéis para cones de trefilação de fios metálicos, assim como polias para tratamento dos mesmos. Esta cerâmica apresenta, entretanto, desestabilização da fase tetragonal quando submetida a soluções ácidas em temperaturas ao redor de $70{ }^{\circ} \mathrm{C}$, condições de processo na indústria de fios metálicos especiais, o que causa desintegração do material. Nesta aplicação a cerâmica Mg-PSZ tem apresentado desempenho superior. Um dos fatores que limitam o maior emprego da cerâmica Mg-PSZ é a sua alta temperatura de sinterização $\left(\sim 1670{ }^{\circ} \mathrm{C}\right.$, limite de forno a gás industrial), em relação à temperatura de sinterização da cerâmica Y-TZP $\left(\sim 1500^{\circ} \mathrm{C}\right)$.

Geralmente as cerâmicas de zircônia são produzidas industrialmente utilizando-se pós comerciais pré-aditivados. Dois pós comerciais largamente empregados para produção de zircônia para fins estruturais são Y-TZP (com 3\% em mol de $\mathrm{Y}_{2} \mathrm{O}_{3}$ ) e Mg-PSZ (com $\sim 3 \%$ em peso de $\mathrm{MgO}$ ). Os preços destes pós, entretanto, são elevados, o que dificulta a ampliação do seu emprego. O preço dos pós de zircônia monoclínica $(\mathrm{ZM})$ é relativamente menor em relação aos preços dos pós de zircônia pré-aditivados. A relação entre os preços comerciais dos pós de Y-TZP, Mg-PSZ e ZM é de cerca de 5:4:1, o que motiva o emprego do pó de ZM para produção de cerâmicas de zircônia. Em um estudo preliminar foram preparadas amostras de PSZ por meio de mistura mecânica de pós utilizando um pó de ZM com os mesmos teores de aditivos dos pós comerciais pré-aditivados. Observou-se, entretanto, que muitas amostras apresentavam-se fraturadas após a sinterização ou não apresentavam desempenho satisfatório na usinagem em retificadora. Decidiu-se, assim, realizar um estudo sistemático, cujos resultados são apresentados neste trabalho, para verificar a possibilidade de se produzir uma cerâmica de PSZ a partir de um pó comercial de ZM de baixo custo pela rota de mistura mecânica de pós. A meta estabelecida foi a obtenção de uma cerâmica de zircônia com as seguintes características: i) apresentar acabamento superficial após usinagem em retificadora cilíndrica com valor de rugosidade $\mathrm{Ra}$ abaixo de $\sim 0,1 \mu \mathrm{m}$; e ii) apresentar pelo menos $\sim 80 \%$ dos valores das propriedades mecânicas (resistência à flexão, dureza e tenacidade à fratura) de uma cerâmica de zircônia parcialmente estabilizada preparada com um pó comercial pré-aditivado com MgO (Mg-PSZ).

\section{MATERIAIS E MÉTODOS}

\section{Materiais de partida}

Foram utilizadas as seguintes matérias-primas:

i) pó granulado de zircônia com $3,20 \%$ em peso $(9,23 \%$ em mol) de $\mathrm{MgO}$, teores de impureza de $0,20 \% \mathrm{Na}_{2} \mathrm{O}$ e $<0,10 \% \mathrm{Al}_{2} \mathrm{O}_{3}, \mathrm{SiO}_{2}, \mathrm{TiO}_{2}, \mathrm{Fe}_{2} \mathrm{O}_{3}$ e $\mathrm{CaO}$, fase monoclínica e tamanho médio de partícula $0,8 \mu \mathrm{m}$;

ii) pó de zircônia monoclínica com 97,14\% $\mathrm{ZrO}_{2}, 1,87 \%$ $\mathrm{HfO}_{2}, 0,49 \% \mathrm{SiO}_{2}, 0,15 \% \mathrm{Y}_{2} \mathrm{O}_{3},<0,10 \% \mathrm{Na}_{2} \mathrm{O}, \mathrm{Al}_{2} \mathrm{O}_{3}, \mathrm{Fe}_{2} \mathrm{O}_{3}$, $\mathrm{CaO}, \mathrm{TiO}_{2}, \mathrm{MgO}$, U e Th;

iii) pó de óxido de ítrio com $<0,01 \% \mathrm{SiO}_{2},<10 \mathrm{ppm}$ $\mathrm{Fe}_{2} \mathrm{O}_{3}$ e tamanho médio de partícula $0,96 \mu \mathrm{m}$; iv) pó de óxido de magnésio (MgO); e

v) pó de carbonato de cálcio $\left(\mathrm{CaCO}_{3}\right)$.

\section{Composições (formulações) dos aditivos}

$\mathrm{Na}$ série I, verificou-se o efeito do teor de adição individual de $\mathrm{MgO}, \mathrm{Y}_{2} \mathrm{O}_{3}$ e $\mathrm{CaO}$ no pó de zircônia monoclínica. As composições investigadas (Tabela I) foram escolhidas dentro do campo de duas fases (cúbica e tetragonal) na temperatura de sinterização, conforme os diagramas de fases $\mathrm{ZrO}_{2}-\mathrm{MgO}$ [32], $\mathrm{ZrO}_{2}-\mathrm{CaO}$ [1] e $\mathrm{ZrO}_{2}$ $\mathrm{Y}_{2} \mathrm{O}_{3}$ [33]. O maior valor de adição de cada aditivo foi estabelecido como sendo o teor limite entre o campo de duas fases e o campo da fase cúbica a $\sim 1700{ }^{\circ} \mathrm{C}$. A amostra M2 apresentou teor de MgO próximo ao do pó granulado comercial MgZ02A. Na série II, verificou-se principalmente o efeito da adição simultânea de $\mathrm{MgO}, \mathrm{Y}_{2} \mathrm{O}_{3}$ e/ou $\mathrm{CaO}$ na zircônia monoclínica. As composições individuais e mistas investigadas estão apresentadas na Tabela II. As composições individuais MF, CF e YF são iguais às composições M3, C3 e Y3, respectivamente, da série I. A diferença entre elas consiste nas diferentes rotas de processamento empregadas para a preparação das suspensões, como descritas abaixo. As composições binárias (MC, MY e CY) foram definidas considerando-se $50 \%$ dos teores individuais dos aditivos (\% em mol) e a composição ternária (MCY) 33\%.

Tabela I - Teores de aditivos das amostras da série I. [Table I - Additive contents of series I samples.]

\begin{tabular}{cccc}
\hline Amostra & $\begin{array}{c}\mathrm{MgO} \\
\text { \% em mol }\end{array}$ & $\begin{array}{c}\mathrm{CaO} \\
\text { (\% em peso) }\end{array}$ & $\mathrm{Y}_{2} \mathrm{O}_{3}$ \\
\hline $\mathrm{M} 1$ & $6,4(2,2)$ & --- & --- \\
$\mathrm{M} 2$ & $8,7(3,0)$ & --- & --- \\
$\mathrm{M} 3$ & $11,0(3,9)$ & --- & --- \\
$\mathrm{C} 1$ & --- & $6,4(3,0)$ & --- \\
$\mathrm{C} 2$ & --- & $8,7(4,2)$ & --- \\
$\mathrm{C} 3$ & --- & $11,0(5,3)$ & --- \\
$\mathrm{Y} 1$ & --- & --- & $3,8(6,8)$ \\
$\mathrm{Y} 2$ & --- & -- & $5,1(9,0)$ \\
$\mathrm{Y} 3$ & --- & -- & $6,4(11,2)$ \\
\hline
\end{tabular}

Tabela II - Teores de aditivos das amostras da série II. [Table II - Additive contents of series II samples.]

\begin{tabular}{cccc}
\hline Amostra & $\begin{array}{c}\mathrm{MgO} \\
\% \text { em mol }\end{array}$ & $\begin{array}{c}\mathrm{CaO} \\
\text { (\% em peso) }\end{array}$ & $\mathrm{Y}_{2} \mathrm{O}_{3}$ \\
\hline $\mathrm{MF}$ & $11,0(3,9)$ & --- & --- \\
$\mathrm{CF}$ & --- & $11,0(5,3)$ & --- \\
$\mathrm{YF}$ & --- & --- & $6,4(11,2)$ \\
$\mathrm{MC}$ & $5,5(1,9)$ & $5,5(2,7)$ & --- \\
$\mathrm{MY}$ & $5,5(1,8)$ & --- & $3,2(5,9)$ \\
$\mathrm{CY}$ & --- & $5,5(2,5)$ & $3,2(5,9)$ \\
$\mathrm{MCY}$ & $3,7(1,2)$ & $3,7(1,7)$ & $2,1(4,0)$ \\
\hline
\end{tabular}




\section{Processamento cerâmico}

A preparação das amostras envolveu:

i) preparação da suspensão (300 g de pós, $250 \mathrm{~mL}$ de água deionizada e agente dispersante); ii) mistura dos pós em moinho de bolas (Yamato, UB32) em recipiente revestido de material polimérico e $3 \mathrm{~kg}$ de elementos cilíndricos de moagem de zircônia: $15 \mathrm{~h}$ de moagem, sendo a última hora realizada com 3\% em peso de ligante PVAc;

iii) secagem em placa aquecedora com agitador magnético; iv) granulação do pó em peneira de náilon de 35 mesh; v) prensagem uniaxial dos pós em matriz cilíndrica (20 $\mathrm{MPa}$, diâmetro de $15 \mathrm{~mm}$ ) seguida de prensagem isostática a $100 \mathrm{MPa}$; e vi) sinterização ao ar em forno elétrico (Yamato, FP 32): patamares intermediários a $300{ }^{\circ} \mathrm{C}$ por $1 \mathrm{~h}$ e $1150{ }^{\circ} \mathrm{C}$ por $5 \mathrm{~h}$, seguidos do patamar de sinterização a 1500,1600 ou $1700{ }^{\circ} \mathrm{C}$ por $5 \mathrm{~h}$; taxa de aquecimento de $3^{\circ} \mathrm{C} / \mathrm{min}$ até $300^{\circ} \mathrm{C}$ e acima desta temperatura de $5^{\circ} \mathrm{C} / \mathrm{min}$, e taxa de resfriamento de $30^{\circ} \mathrm{C} / \mathrm{min}$.

Na preparação dos pós, o $\mathrm{CaO}$ foi adicionado na forma de $\mathrm{CaCO}_{3}$. A quantidade de carbonato foi calculada com base na perda de massa teórica deste composto. Na preparação dos pós da série I de aditivos (Tabela I), utilizou-se ácido nítrico como agente dispersante. Adicionou-se cerca de 20 a $60 \mathrm{~mL}$ deste ácido, dependendo do teor e do tipo do aditivo, para a preparação de suspensões dispersas com $\mathrm{pH}$ ao redor de 2,5 [34]. Na preparação dos pós da série II de aditivos (Tabela II), utilizou-se 1\% em peso de hexametafosfato de sódio (Fluka) como agente dispersante.

Corpos verdes preparados com o pó granulado de zircônia (MgZ02A), denominado M0, também foram sinterizados junto com os corpos preparados com os demais pós, como material de controle. Em cada condição de sinterização, foram preparados três corpos sinterizados de cada pó na forma de cilindros com diâmetro entre $\sim 11$ e $12 \mathrm{~mm}$ e altura entre $\sim 15$ e $20 \mathrm{~mm}$.

\section{Caracterização}

As seguintes técnicas de caracterização foram empregadas:

i) análise granulométrica dos pós (Micromeritics, Sedigraph 5000 ET); ii) densidade aparente dos corpos compactados: método geométrico; iii) densidade e porosidade aparentes dos corpos sinterizados: princípio de Arquimedes com impregnação de água sob vácuo; iv) "teste" de usinagem: seqüência de 3 rebolos adiamantados (grosso, médio e fino) em retificadora cilíndrica (Toss) e determinação da rugosidade média aritmética (Ra, Mitutoyo, Surftest 301) das superfícies usinadas. Em geral foram ensaiados dois corpos-de-prova por amostra, tendo sido realizadas três medições de rugosidade em cada corpode-prova; v) análise por difração de raios X (DRX, Bruker, D8 Focus): realizada em amostras com superfícies polidas utilizando geometria Bragg-Brentano, radiação $\mathrm{Cu} \mathrm{K \alpha}, 40$ $\mathrm{kV}, 40 \mathrm{~mA}$, (20) 20 a $140^{\circ}$, passo de $0,02^{\circ}$, fenda de emissão de $0,6 \mathrm{~mm}$ e fenda de recepção de $0,1 \mathrm{~mm}$. As frações em peso das fases cristalinas foram determinadas pelo método Rietveld com programa Topas 3.0 (Bruker); vi) análise por microscopia eletrônica de varredura (MEV, Jeol, JSM-6300). Para a análise quantitativa do tamanho de grão, as amostras polidas foram atacadas termicamente a $1420{ }^{\circ} \mathrm{C}$ por $10 \mathrm{~min}$ e a medição foi realizada em um analisador de imagens (Leica, QWin). Pelo menos 500 grãos foram avaliados em cada amostra; vii) dureza Vickers (Tukon): foram realizadas quatro indentações em superfícies polidas de cada amostra com carga de 10 kgf (HV10). Esta carga foi escolhida por dois motivos: é uma das cargas recomendadas pela norma JIS R 1610-1991 “Testing method for Vickers hardness of high performance ceramics" (a outra carga é 1 kgf); e gerou trincas suficientemente longas nos cantos da impressão para a determinação confiável da tenacidade à fratura pelo método de fratura por indentação (IF); viii) tenacidade à fratura, $\mathrm{K}_{\mathrm{Ic}}$, pelo método IF: foram utilizadas as mesmas indentações de determinação de dureza Vickers. A relação entre os comprimentos da trinca e da diagonal de impressão (c/a) variou entre $\sim 1,8$ e 3,2 para as amostras analisadas. Para o cálculo de $\mathrm{K}_{\mathrm{Ic}}$ utilizou-se a equação empírica proposta por Evans e Charles [35]:

$$
\mathrm{K}_{\mathrm{Ic}}=0,0732\left(\frac{\mathrm{E}}{\mathrm{H}}\right)^{0,4} \mathrm{Ha}^{0,5}\left(\frac{\mathrm{c}}{\mathrm{a}}\right)^{-1,5}
$$

onde, E é o módulo de elasticidade, H é a dureza Vickers, a é a metade da diagonal de impressão e c é a metade do comprimento da trinca radial. Ressalta-se que a Eq. A foi ajustada para uma larga faixa de valores de c/a ( 1,5 a 7) e conceitualmente proposta pelos autores para trinca radialmediana [35]. Niihara et al. [36], entretanto, observaram que na faixa de baixos valores de c/a a trinca radial é do tipo Palmqvist e propuseram uma equação semi-analítica para a faixa de c/a de $\sim 1,25$ a 3,0 utilizando, entre outros, os resultados de Evans e Charles [35]. Assim, a Eq. A pode ser considerada uma equação empírica "universal" tanto para a faixa de trinca radial do tipo mediana como Palmqvist. Como o valor de c/a que distingue a transição entre os dois tipos de trinca não é conhecido (por ex., a equação semi-analítica de Anstis et al. [37] para trinca radial-mediana é válida para c/a $\sim 2$ ), optou-se neste trabalho por utilizar a Eq. A, que independe do tipo da trinca radial. Há uma equação semianalítica "universal" proposta tanto para a faixa de trinca radial-mediana como Palmqvist, que depende, entre outras variáveis, do coeficiente de Poisson, v [38]. A utilização desta equação apresentou resultados inconsistentes com os resultados de outras equações e mostrou que o valor calculado é muito sensível a pequenas variações no valor do coeficiente de Poisson (por ex., um pequeno aumento de $v, 0,02$, resultou em variação de uma ordem de grandeza no valor de $\mathrm{K}_{\mathrm{Ic}}$ calculado);

ix) módulo de elasticidade, E, e coeficiente de Poisson, $v$ : método do pulso-eco ultrassônico. Utilizou-se um emissor/receptor de pulso ultrassônico (Panametrics, 5900 $\mathrm{PR}$ ) e transdutores de onda longitudinal e transversal para 
determinação dos tempos de vôo do pulso. As velocidades sônicas foram calculadas dividindo-se o dobro da espessura, medida com um micrômetro digital (Mitutoyo), pelos tempos de vôo. Os valores de E e $v$ foram calculados por meio das seguintes equações:

$$
\begin{aligned}
& E=\rho\left(\frac{3 V_{T}^{2} V_{L}^{2}-4 V_{T}^{4}}{V_{L}^{2}-V_{T}^{2}}\right) \\
& v=0,5 \frac{V_{L}^{2}-2 V_{T}^{2}}{V_{L}^{2}-V_{T}^{2}}
\end{aligned}
$$

onde, $\rho$ é a densidade e $V_{L}$ e $V_{T}$ são, respectivamente, as velocidades longitudinal e transversal do pulso ultrassônico; x) resistência à flexão biaxial: método do pistão sobre três esferas (piston on three balls). Utilizou-se um dispositivo de aço temperado com três esferas de 1,60 mm de diâmetro posicionadas eqüidistantes em um círculo de $4 \mathrm{~mm}$ de raio e um punção cilíndrico de carregamento com raio de 0,82 $\mathrm{mm}$. Quatro corpos-de-prova na forma de disco de cada amostra foram preparados por meio de corte com serra diamantada em uma cortadeira de alta rotação (Buehler, Isomet 2000). Os ensaios foram realizados com velocidade da travessa de $0,5 \mathrm{~mm} / \mathrm{min}$ e célula de carga de $500 \mathrm{~N}$ em um equipamento de ensaios mecânicos (MTS, Syntech 5G). $\mathrm{O}$ valor de resistência à flexão biaxial, $\mathrm{S}$, foi calculado por meio das equações dadas na norma ASTM F 394-1978 (1991) "Standard test method for biaxial flexure strength (modulus of rupture) of ceramic substrates":

$$
\begin{aligned}
& S=-0,2387 \frac{P(X-Y)}{d^{2}} \\
& X=(1+v) \ln (B / C)^{2}+[(1-v) / 2](B / C)^{2} \\
& Y=(1+v)\left[1+\ln (\mathrm{A} / \mathrm{C})^{2}\right]+(1-v)(A / C)^{2}
\end{aligned}
$$

onde, $\mathrm{P}$ é a carga de fratura, $\mathrm{d}$ é a espessura da amostra (cerca de 0,8 mm), $v$ é o coeficiente de Poisson, A é o raio do círculo suporte (4 mm), B é o raio da área de carregamento $(0,82 \mathrm{~mm})$ e C é o raio do corpo-de-prova (cerca de $6 \mathrm{~mm}$ ).

\section{RESULTADOS E DISCUSSÃO}

$\mathrm{O}$ pó de $\mathrm{ZrO}_{2}$ monoclínico (CF-Super-HM) apresentou tamanho de partícula médio $\left(\mathrm{D}_{50}\right)$ de $1,1 \mu \mathrm{m}$ e larga distribuição granulométrica $\left(D_{10}\right.$ e $D_{90}$ de 0,45 e $7,0 \mu \mathrm{m}$, respectivamente). A análise por MEV mostrou aglomerados de partículas finas e partículas grandes de até $\sim 10 \mu \mathrm{m}$ (Fig. 1a). A Fig. 1b apresenta uma imagem de baixo aumento do pó granulado M0 (MgZ02A), onde se observa a presença de grânulos com forma esférica. Os padrões de DRX destes pós apresentaram apenas fase monoclínica.

As fases identificadas nos padrões de difração de todas
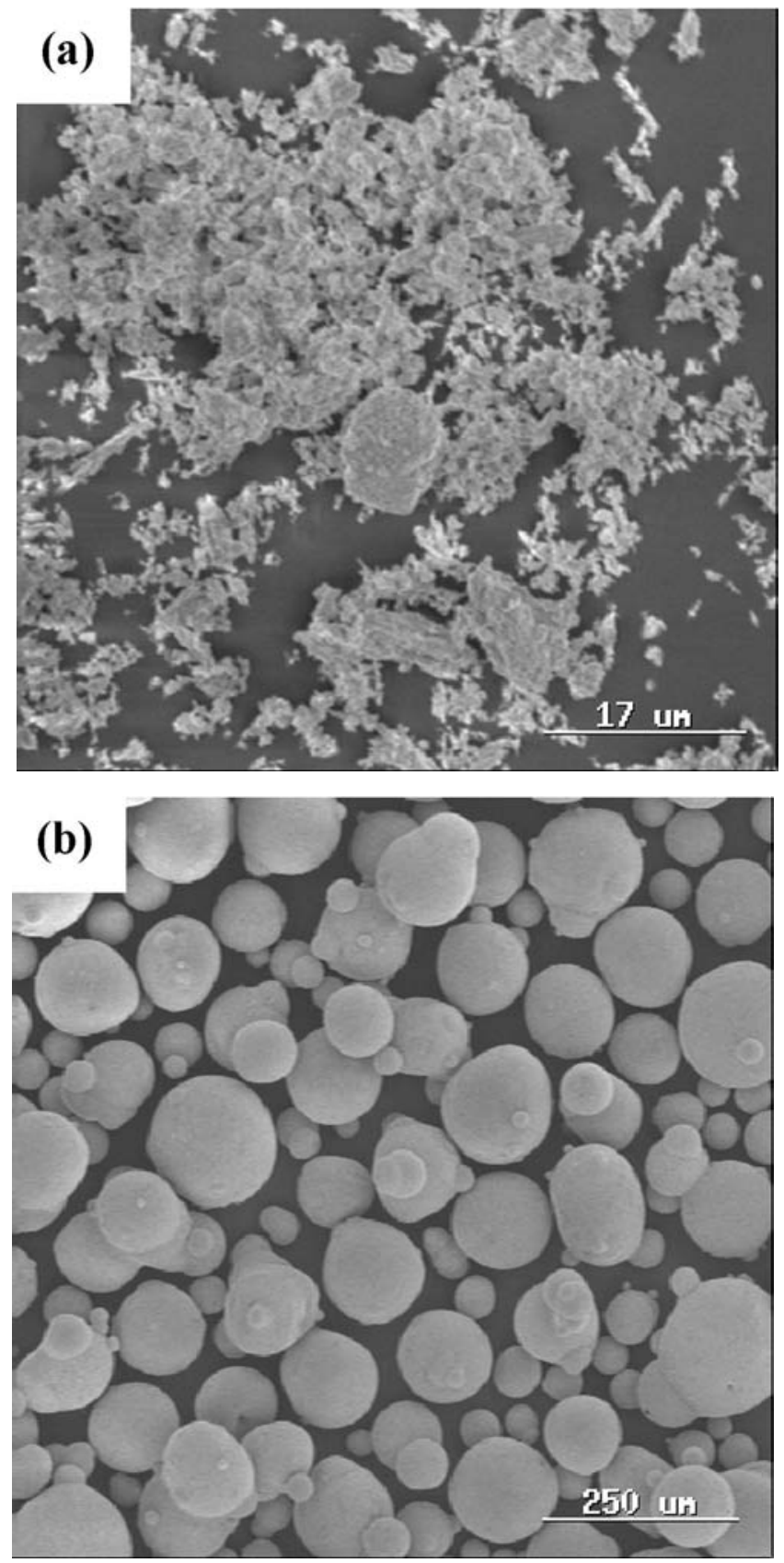

Figura 1: Imagens de MEV: (a) pó de $\mathrm{ZrO}_{2}$ monoclínico e (b) pó granulado M0.

[Figure 1: SEM images: (a) monoclinic $\mathrm{ZrO}_{2}$ powder, and (b) granulated powder M0.]

as amostras sinterizadas entre 1500 e $1700{ }^{\circ} \mathrm{C}$ foram as fases polimórficas da zircônia: monoclínica, tetragonal e cúbica. A Fig. 2 apresenta os resultados de fração da fase monoclínica em função da temperatura de sinterização. Na amostra de referência, M0, a fração de fase monoclínica foi de $26 \%$ a $1500{ }^{\circ} \mathrm{C}$ e diminuiu para $4 \%$ a $1600{ }^{\circ} \mathrm{C}$ e mantevese constante a $1700^{\circ} \mathrm{C}$. Já nas amostras da série I (M1 a Y3, Tabela I), o aumento do teor de aditivo ( $\mathrm{MgO}, \mathrm{CaO}$ e $\mathrm{Y}_{2} \mathrm{O}_{3}$ ) causou, em geral, diminuição da fração de fase monoclínica. As frações de fase monoclínica não estabilizadas destas amostras, entretanto, foram significativamente maiores 


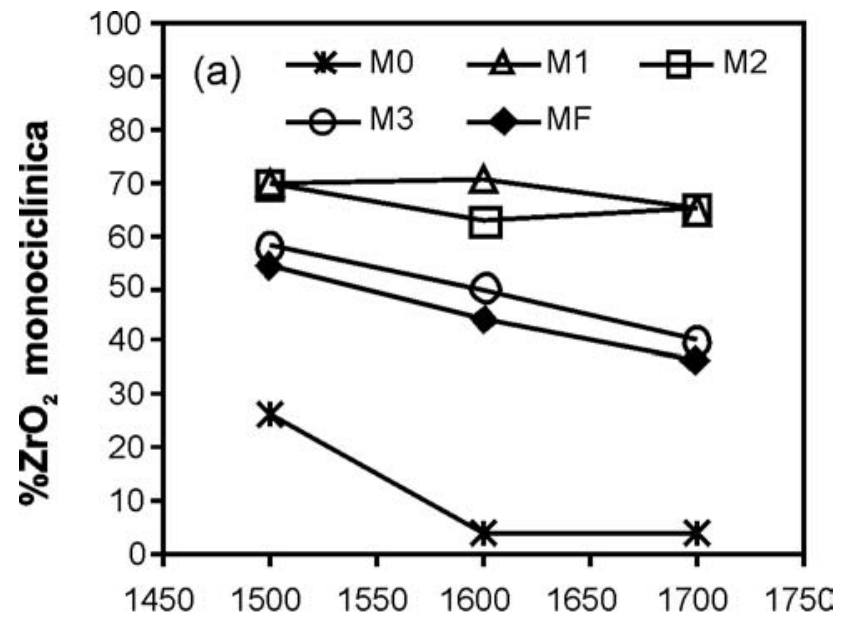

Temperatura de sinterização $\left({ }^{\circ} \mathrm{C}\right)$

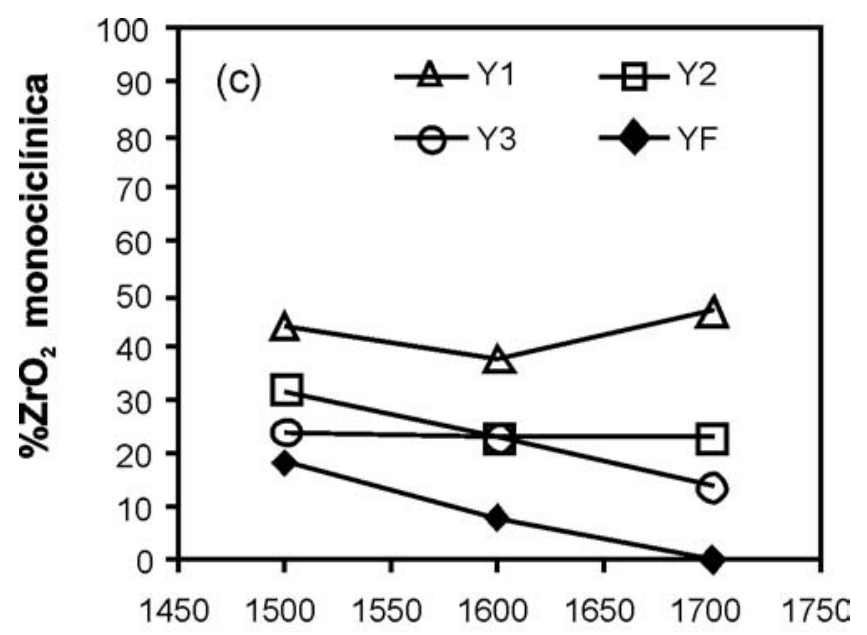

Temperatura de sinterização $\left({ }^{\circ} \mathrm{C}\right)$

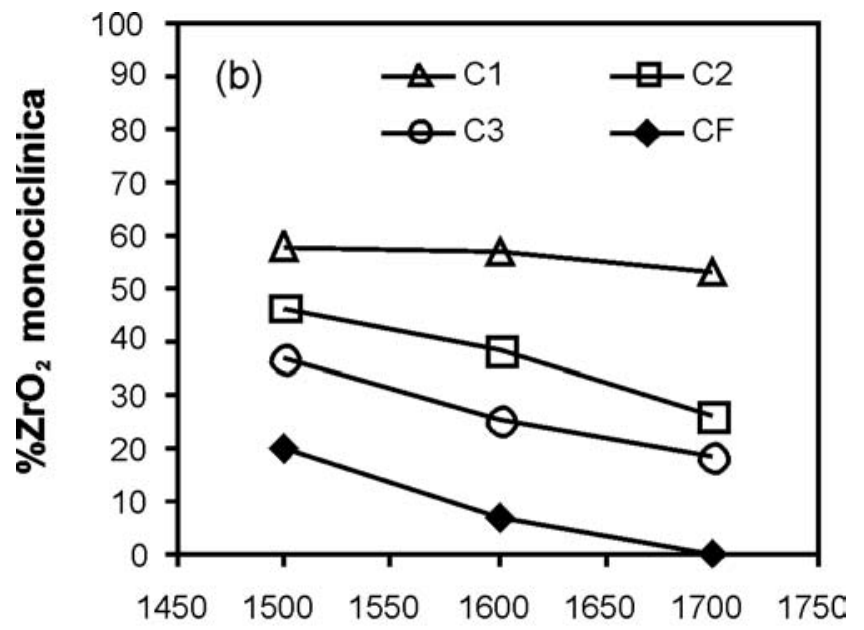

Temperatura de sinterização $\left({ }^{\circ} \mathrm{C}\right)$

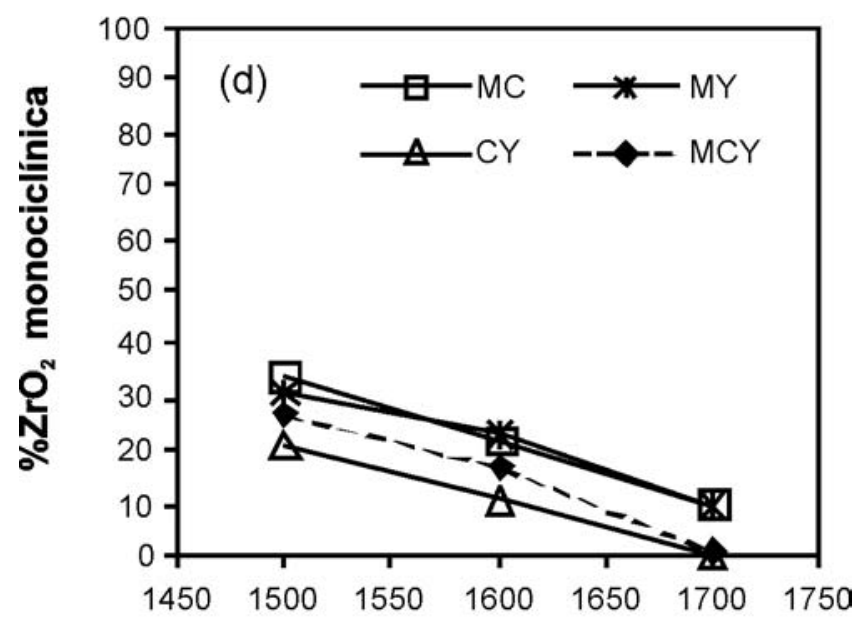

Temperatura de sinterização $\left({ }^{\circ} \mathrm{C}\right)$

Figura 2: Fração de fase zircônia monoclínica das amostras sinterizadas com adições de: (a) $\mathrm{MgO}$; (b) $\mathrm{CaO}$; (c) $\mathrm{Y}_{2} \mathrm{O}_{3}$; e (d) mistura de $\mathrm{MgO}$, $\mathrm{CaO}$ e/ou $\mathrm{Y}_{2} \mathrm{O}_{3}$.

[Figure 2: Fraction of monoclinic zirconia phase of the samples sintered with additions of: (a) $\mathrm{MgO}$; (b) $\mathrm{CaO}$; (c) $\mathrm{Y}_{2} \mathrm{O}_{3}$; and (d) mixture of $\mathrm{MgO}, \mathrm{CaO}$ and/or $\mathrm{Y}_{2} \mathrm{O}_{3}$.]

do que a da amostra de referência. Comparando-se os resultados entre os diferentes aditivos, observou-se que o MgO (Fig. 2a) teve o pior desempenho em estabilizar as fases de alta temperatura (tetragonal e cúbica) e o $\mathrm{Y}_{2} \mathrm{O}_{3}$ (Fig. 2c) o melhor desempenho, enquanto os resultados das amostras com $\mathrm{CaO}$ (Fig. 2b), principalmente com maiores teores de adição, se aproximaram mais das amostras com $\mathrm{Y}_{2} \mathrm{O}_{3}$. Em geral, o aumento da temperatura de sinterização causou diminuição da fração de fase monoclínica em todas as amostras, entretanto a diminuição foi menor nas amostras com baixos teores de aditivos (M1, M2, C1 e Y1).

As frações de fase monoclínica das amostras com adições individuais da série II (MF, CF e YF), principalmente com adições de $\mathrm{CaO}$ e $\mathrm{Y}_{2} \mathrm{O}_{3}$, foram menores do que as frações das respectivas amostras similares, em termos de teor de aditivos, da série I (M3, C3 e Y3, Figs. 2a a 2c). Este resultado indicou que a rota de preparação dos pós influenciou na estabilização das fases, sendo que a utilização de hexametafosfato de sódio, como dispersante nas suspensões da série II, foi melhor para a estabilização das fases de alta temperatura durante a sinterização do que o uso de ácido nítrico ( $\mathrm{pH} 2,5$ na série I). Não foi possível identificar o motivo desta diferença de comportamento. A preparação de suspensão com pH 2,5 foi sugerida por Lange [34] para favorecer a ruptura de aglomerados duros de partículas finas de zircônia. É possível que a utilização de ácido nítrico tenha causado alterações nos pós com formações de compostos, como nitratos, entretanto, a análise de DRX dos pós granulados não indicou a formação destes compostos. Em termos industriais, a utilização de um dispersante, como o hexametafosfato de sódio, apresenta 
vantagens em relação ao manuseio de suspensões ácidas, tanto do aspecto de corrosão quanto ambiental.

As frações de fase monoclínica não estabilizada das amostras CF (Fig. 2b), YF (Fig. 2c) e CY (Fig. 2d) foram similares à da amostra de referência, M0 (Fig. 2a). Já as amostras com adições mistas da série II contendo MgO (MC, MY e MCY) apresentaram maiores frações de fase monoclínica do que a amostra CY (Fig. 2d), ratificando a constatação acima de que o MgO tem desempenho inferior ao $\mathrm{CaO}$ e $\mathrm{Y}_{2} \mathrm{O}_{3}$ para estabilização das fases de alta temperatura (tetragonal e cúbica). Embora algumas composições de aditivos tenham resultado em frações de fase monoclínica similar à amostra de referência, isto foi possível com a utilização de elevados teores de aditivos (Tabela II). Assim, o pó de $\mathrm{ZrO}_{2}$ monoclínico utilizado apresentou dificuldade de estabilização das fases de alta temperatura, provavelmente devido à presença de grandes partículas (até $\sim 10 \mu \mathrm{m}$ ) neste pó (Fig. 1a). A difusão dos aditivos para o interior das partículas foi, assim, favorecido pelo maior teor de aditivos (maior potencial químico) e pelo aumento da temperatura de sinterização.

A quantificação da fração da fase zircônia monoclínica é relativamente simples. Porém, o problema de diferenciar as formas alotrópicas cúbica e tetragonal não é trivial, pois as duas estruturas são praticamente idênticas, ou seja, os padrões de difração de raios $\mathrm{X}$ são praticamente idênticos para ambas as estruturas. Como a multiplicação do parâmetro a do tetragonal por $\sqrt{ } 2$ resulta no parâmetro de rede do cúbico, pode-se definir "tetragonalidade" como a razão a $\sqrt{2}$ /c. Quando este número é 1 , tem-se um reticulado cúbico. Freqüentemente esse número é próximo de 1 na zircônia, o que dificulta significativamente a diferenciação entre as fases tetragonal e cúbica [39, 40]. O procedimento possível para se distinguir a fase cúbica da tetragonal é estipular os parâmetros de rede de ambas as fases [30, 31, 41, 42]. Quando elementos diferentes são adicionados simultaneamente, esse procedimento torna-se complexo, pois podem ocorrer variações dos parâmetros de rede das formas alotrópicas cúbica e tetragonal, cujos valores não estão descritos na literatura. Considerando que alguns elementos em solução sólida favorecem a forma alotrópica tetragonal, como $\mathrm{Y}$, enquanto outros, como $\mathrm{Mg}$ e $\mathrm{Ca}$, favorecem a cúbica [15, 27], pode haver diferença de distribuição dos elementos nas várias formas alotrópicas, o que complica a análise. Também outros aspectos, como heterogeneidade de distribuição dos aditivos nos grãos de zircônia, podem influir. Possivelmente as amostras investigadas apresentaram gradientes de composição dos aditivos associadas, principalmente, às partículas grandes do pó de partida (Fig. 1a), o que pode ter causado o "alargamento" dos picos e favorecido a superposição dos picos, dificultando a distinção entre as fases cúbica e tetragonal. Em decorrência destas dificuldades, não foi possível quantificar as frações das fases cúbica e tetragonal com precisão pelo método de Rietveld até o momento. Por ex., em uma amostra analisada foram fixados os parâmetros das fases tetragonal $(a=3,61$ $\AA$, c=5,12 $\AA$ ) e cúbica ( $a=5,09 \AA$ ), o que resultou em 5\% cúbica e $60 \%$ tetragonal. Quando se aumentou ligeiramente apenas o parâmetro da cúbica (a=5,12 $\AA$ ), o resultado foi 44,5\% cúbica e 22,5\% tetragonal. Já pequenas alterações nos parâmetros da tetragonal (a=3,58 $\AA$, c=5,16 $\AA$ ), mantendo-se a cúbica (a=5,12 $\AA$ ), o resultado foi $55 \%$ cúbica e $12 \%$ tetragonal. Nas três análises o valor de Rwp $(R$ weighted pattern) foi baixo $(\sim 15 \%)$ indicando bons ajustes do espectro, entretanto as variações das quantificações alcançaram diferenças de até uma ordem de grandeza. Embora não tenha sido possível quantificar as frações das fases cúbica e tetragonal, os diagramas de fases da zircônia com os aditivos [1, 32, 33] mostram que, no campo destas duas fases, quanto maior a temperatura de sinterização menor é a fração da fase tetragonal. Assim, é de se esperar que as amostras sinterizadas a $1700{ }^{\circ} \mathrm{C}$ apresentaram frações de fase tetragonal menores do que as mesmas sinterizadas a $1500{ }^{\circ} \mathrm{C}$.

A Tabela III apresenta os resultados da análise visual das amostras sinterizadas entre 1500 e $1700{ }^{\circ} \mathrm{C}$. A amostra de controle, M0, apresentou corpos sinterizados íntegros, sem fratura, nas três temperaturas de sinterização. Em geral, as amostras com baixos teores de aditivos (M1, M2, C1, Y1 e Y2) apresentaram corpos sinterizados com fraturas macroscópicas. Provavelmente, este comportamento está associado às altas frações de fase monoclínica observadas nestas amostras (Fig. 2). A relação entre a obtenção de corpos sinterizados íntegros e a fração de fase monoclínica, entretanto, depende do tipo de aditivo, uma vez que as amostras M3, MF e C2 apresentaram corpos íntegros e maiores frações de fase monoclínica do que a amostra Y2 (Fig. 2). As amostras com adição apenas de $\mathrm{Y}_{2} \mathrm{O}_{3}$ apresentaram comportamento que dependeu do teor de aditivo e da temperatura de sinterização. As amostras com baixos teores de $\mathrm{Y}_{2} \mathrm{O}_{3}(\mathrm{Y} 1$ e $\mathrm{Y} 2$ ) apresentaram corpos

Tabela III - Resultados da análise visual de integridade das amostras sinterizadas a $1500{ }^{\circ} \mathrm{C}, 1600{ }^{\circ} \mathrm{C}$ e $1700{ }^{\circ} \mathrm{C}$ : I - íntegro; e F -fraturado.

[Table III - Visual inspection results of body integrity of samples sintered at $1500{ }^{\circ} \mathrm{C}, 1600{ }^{\circ} \mathrm{C}$ and $1700{ }^{\circ} \mathrm{C}$ : I - without fracture; and $F$ - fractured.]

\begin{tabular}{ccccccccccccccccccc}
\hline $\begin{array}{c}\text { T } \\
\left({ }^{\circ} \mathrm{C}\right)\end{array}$ & MO & M1 & M2 & M3 & C1 & C2 & C3 & Y1 & Y2 & Y3 & MF & CF & YF & MC & MY & CY & MCY \\
\hline 1500 & I & F & F & I & F & I & I & I & I & F & I & I & I & I & I & I & I \\
1600 & I & F & F & I & F & I & I & F & F & I & I & I & I & I & I & I & I \\
1700 & I & F & F & I & F & I & I & F & F & I & I & I & I & I & I & I & I \\
\hline
\end{tabular}



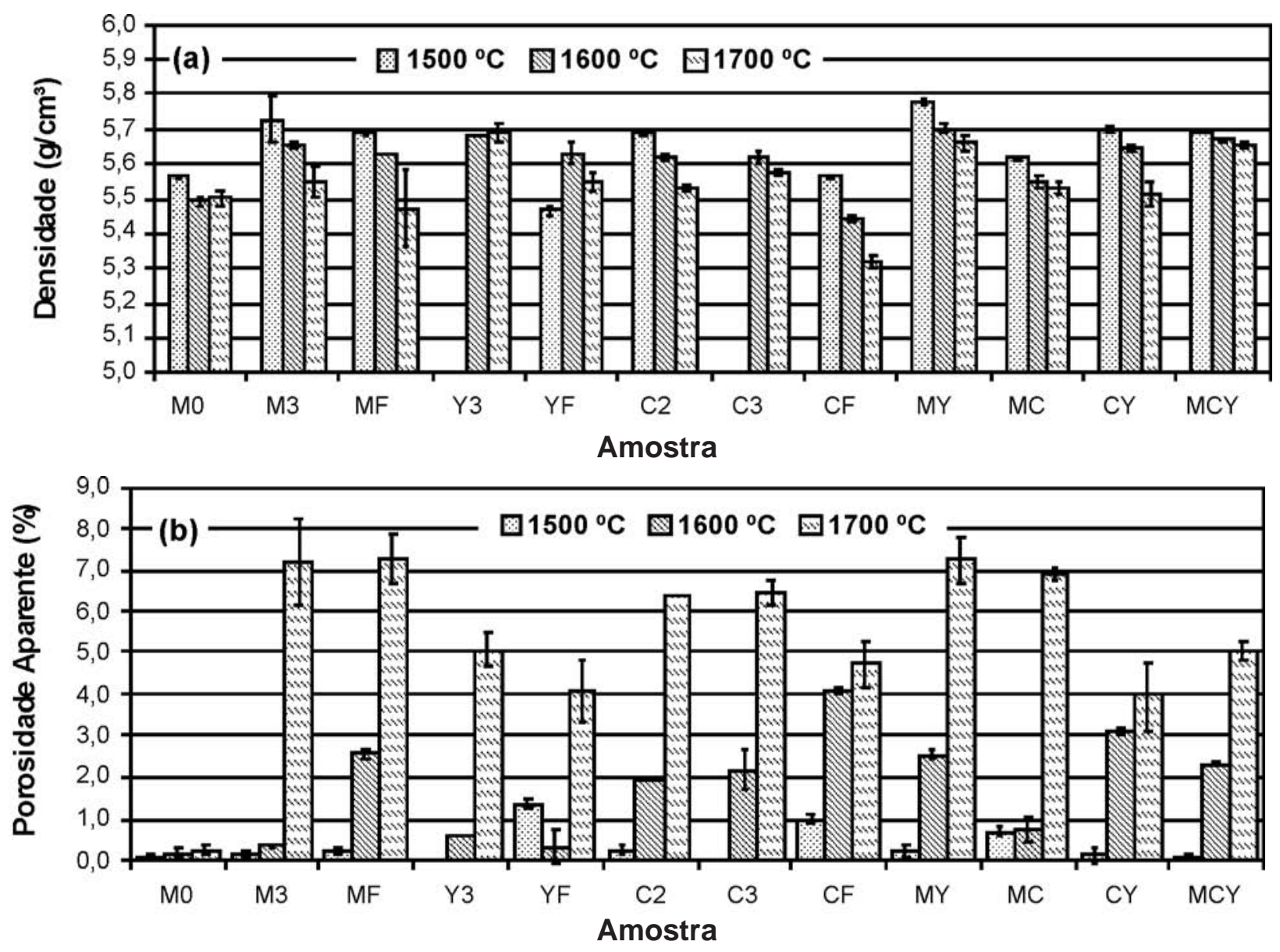

Figura 3: Densidade aparente (a) e porosidade aparente (b) das amostras sinterizadas a 1500, 1600 e $1700{ }^{\circ} \mathrm{C}$. [Figure 3: Apparent density (a) and apparent porosity (b) of the samples sintered at 1500, 1600, and $1700^{\circ} \mathrm{C}$.]

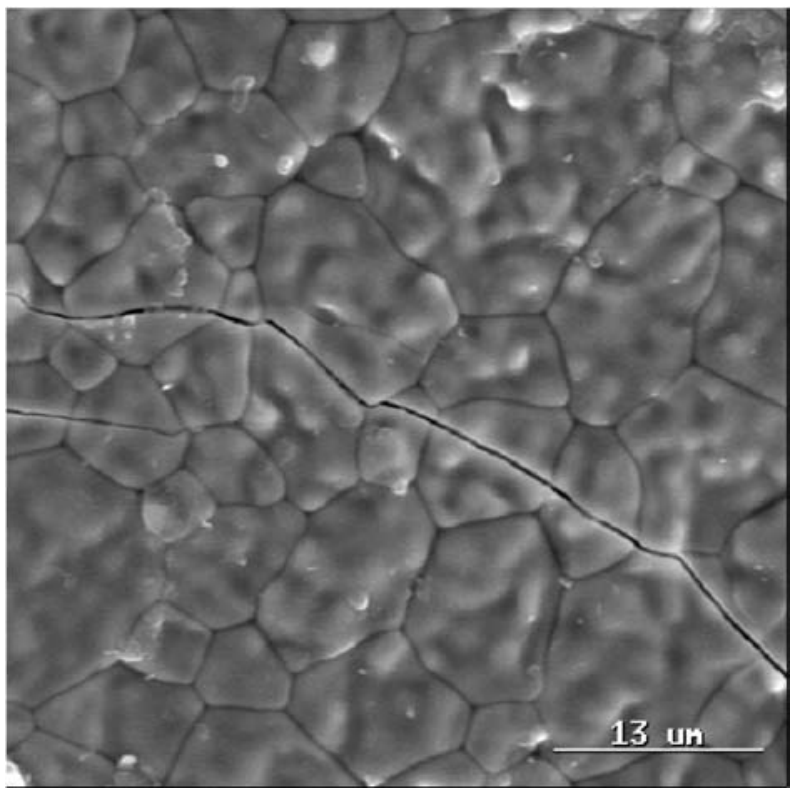

Figura 4: Micrografia de MEV da superfície como sinterizada da amostra Y3 sinterizada a $1700^{\circ} \mathrm{C}$ mostrando presença de microtrincas superficiais.

[Figure 4: SEM micrograph of the as-sintered surface of Y3 sample sintered at $1700^{\circ} \mathrm{C}$ showing the presence of superficial micro-cracks.] íntegros após sinterização a $1500{ }^{\circ} \mathrm{C}$ e fraturados acima desta temperatura, enquanto a amostra com alto teor de $\mathrm{Y}_{2} \mathrm{O}_{3}(\mathrm{Y} 3)$ apresentou corpos fraturados após sinterização a $1500{ }^{\circ} \mathrm{C}$ e íntegros acima desta temperatura. Estes resultados não podem ser explicados apenas pela fração de fase monoclínica (Fig. 2c). As amostras M3, C2 e C3 da série I e todas as amostras da série II (MF, CF, YF, MC, MY, CY e MCY) apresentaram corpos macroscopicamente íntegros em todas as temperaturas de sinterização, sendo a característica comum a elas os elevados teores de aditivos.

A Fig. 3 apresenta os resultados de densidade e porosidade aparentes das amostras sinterizadas e que não apresentaram fraturas macroscópicas. A densidade aparente de todas amostras variou entre cerca de 5,3 e 5,8 g/ $\mathrm{cm}^{3}$. Em geral, com o aumento da temperatura de sinterização, as amostras apresentaram diminuição da densidade (Fig. 3a) e aumento da porosidade aparente, principalmente a 1700 ${ }^{\circ} \mathrm{C}$ (Fig. 3b). Microtrincas foram observadas nas superfícies de algumas amostras sinterizadas a $1700^{\circ} \mathrm{C}$, cujos aspectos indicaram que elas foram formadas durante o estágio de resfriamento do ciclo de sinterização (Fig. 4). Os altos valores de porosidade aparente (Fig. 3b) parecem estar relacionados com as microtrincas superficiais, uma vez que não foram observadas quantidades significativas de poros 
abertos nas amostras sinterizadas. Excetuando a amostra YF, as amostras sinterizadas a $1500{ }^{\circ} \mathrm{C}$ apresentaram baixos valores de porosidade aparente de cerca de $1 \%$ ou menos (Fig. 3b).

A Fig. 5 apresenta os resultados de rugosidade superficial $\mathrm{Ra}$ das amostras submetidas à usinagem em retificadora cilíndrica. Os resultados marcados com * indicam que os corpos-de-prova apresentaram fratura durante a usinagem. As amostras Y3, C2 e C3 sinterizadas a $1700^{\circ} \mathrm{C}$ apresentaram superfícies usinadas com elevados valores de rugosidade e os corpos fraturaram durante a usinagem, possivelmente devido à presença das microtrincas nas superfícies (Fig. 4). As demais amostras apresentaram, em geral, valores de rugosidade $\mathrm{Ra}$ inferiores a $0,15 \mu \mathrm{m}$. As amostras que não fraturaram e apresentaram rugosidade inferior a 0,10 $\mu \mathrm{m}$ em pelo menos uma temperatura de sinterização foram: M0, M3, MF, YF, MY, MC, CY e MCY. Em geral, os valores de rugosidade destas amostras foram pouco influenciados pela temperatura de sinterização, indicando que a fração de fase monoclínica, que diminuiu com o aumento da temperatura de sinterização (Fig. 2), teve pouco efeito no desempenho de usinagem dos corpos sinterizados. Os resultados das amostras C2, C3 e CF, que apresentaram frações de fase monoclínica significativamente diferentes entre si (Fig. 2b), também indicaram que a rugosidade superficial foi pouco influenciada pelas fases presentes nas amostras.

A Fig. 6 apresenta os resultados de resistência à flexão biaxial das amostras sinterizadas entre 1500 e $1700{ }^{\circ} \mathrm{C}$. O

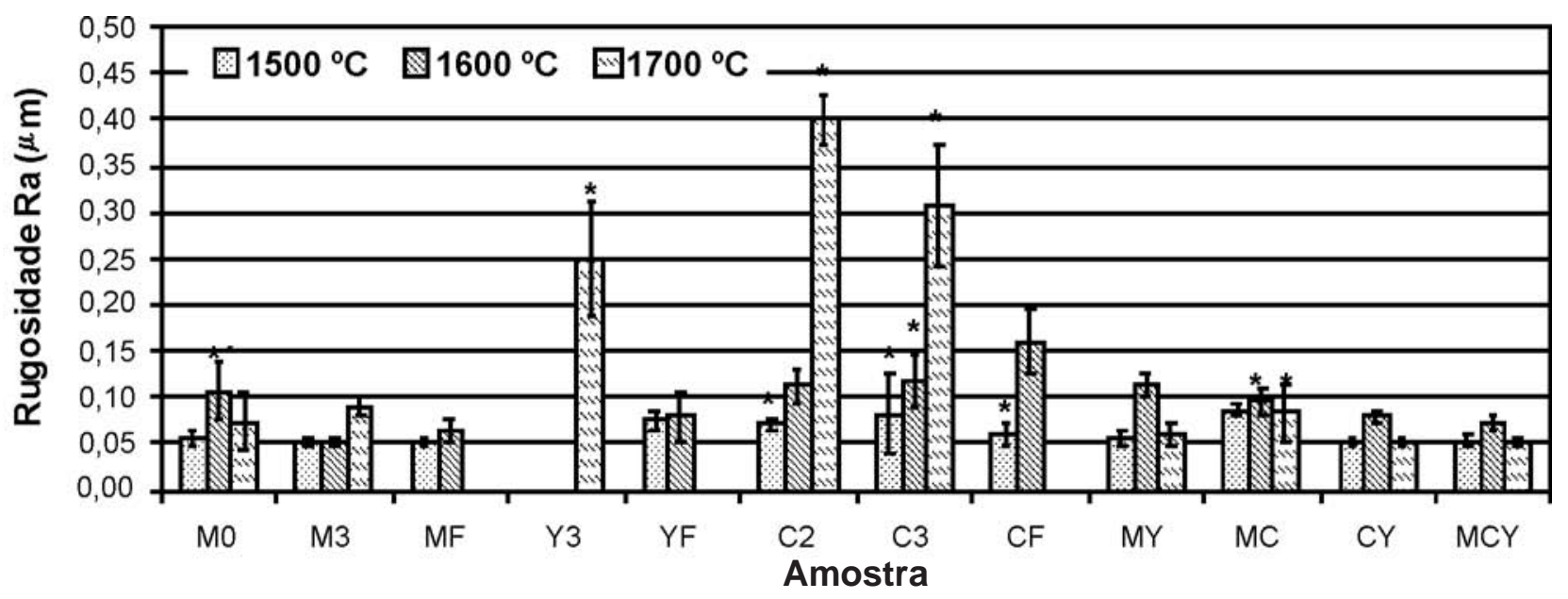

Figura 5: Rugosidade média aritmética (Ra) das amostras sinterizadas a 1500, 1600 e $1700{ }^{\circ} \mathrm{C}$. O símbolo * indica que os dois corpos-deprova ensaiados apresentaram fratura durante a usinagem em retificadora cilíndrica e o símbolo *' na amostra M0 indica que apenas um corpo-de-prova apresentou fratura.

[Figure 5: Arithmetical mean roughness (Ra) of the samples sintered at 1500, 1600, and $1700{ }^{\circ} \mathrm{C}$. The symbol * indicates that the two tested specimens fractured during the centerless grinding operation, and the symbol *' of the sample M0 indicates that only one specimen fractured.]

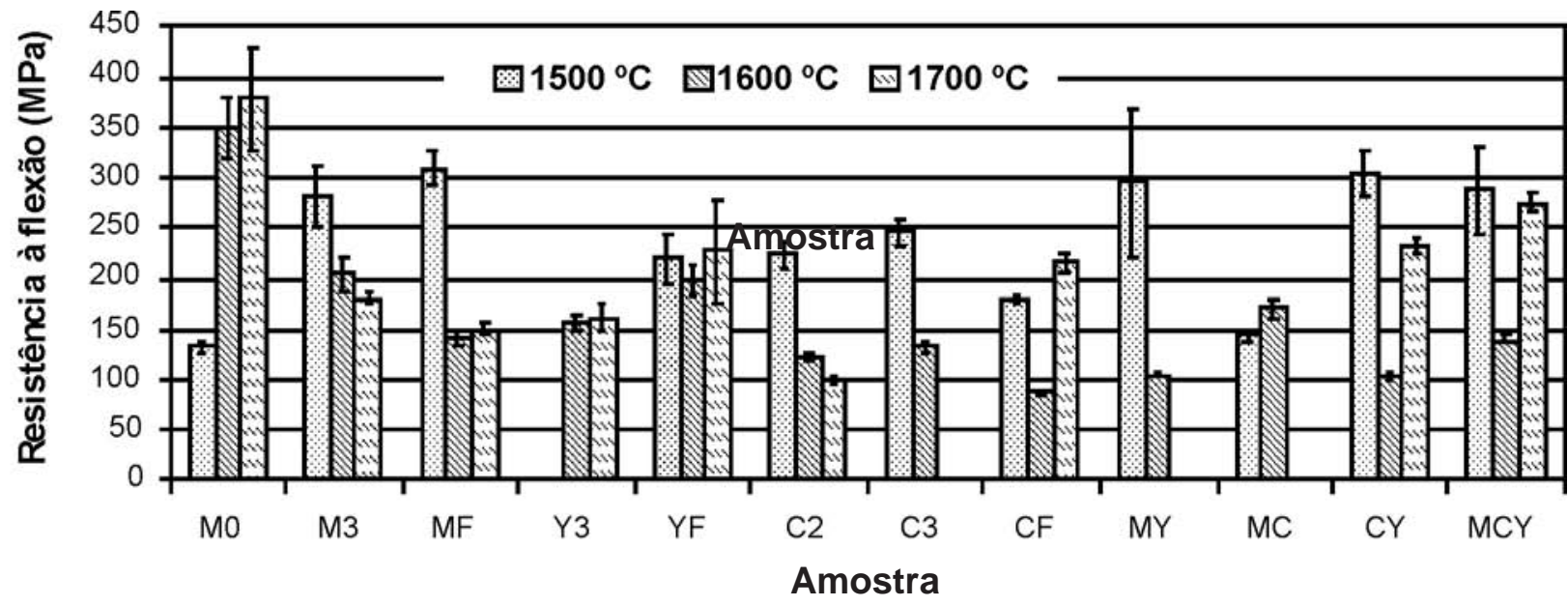

Figura 6: Resistência à flexão biaxial das amostras sinterizadas a 1500,1600 e $1700{ }^{\circ} \mathrm{C}$.

[Figure 6: Biaxial flexural strength of the samples sintered at 1500,1600 , and $1700^{\circ} \mathrm{C}$.] 

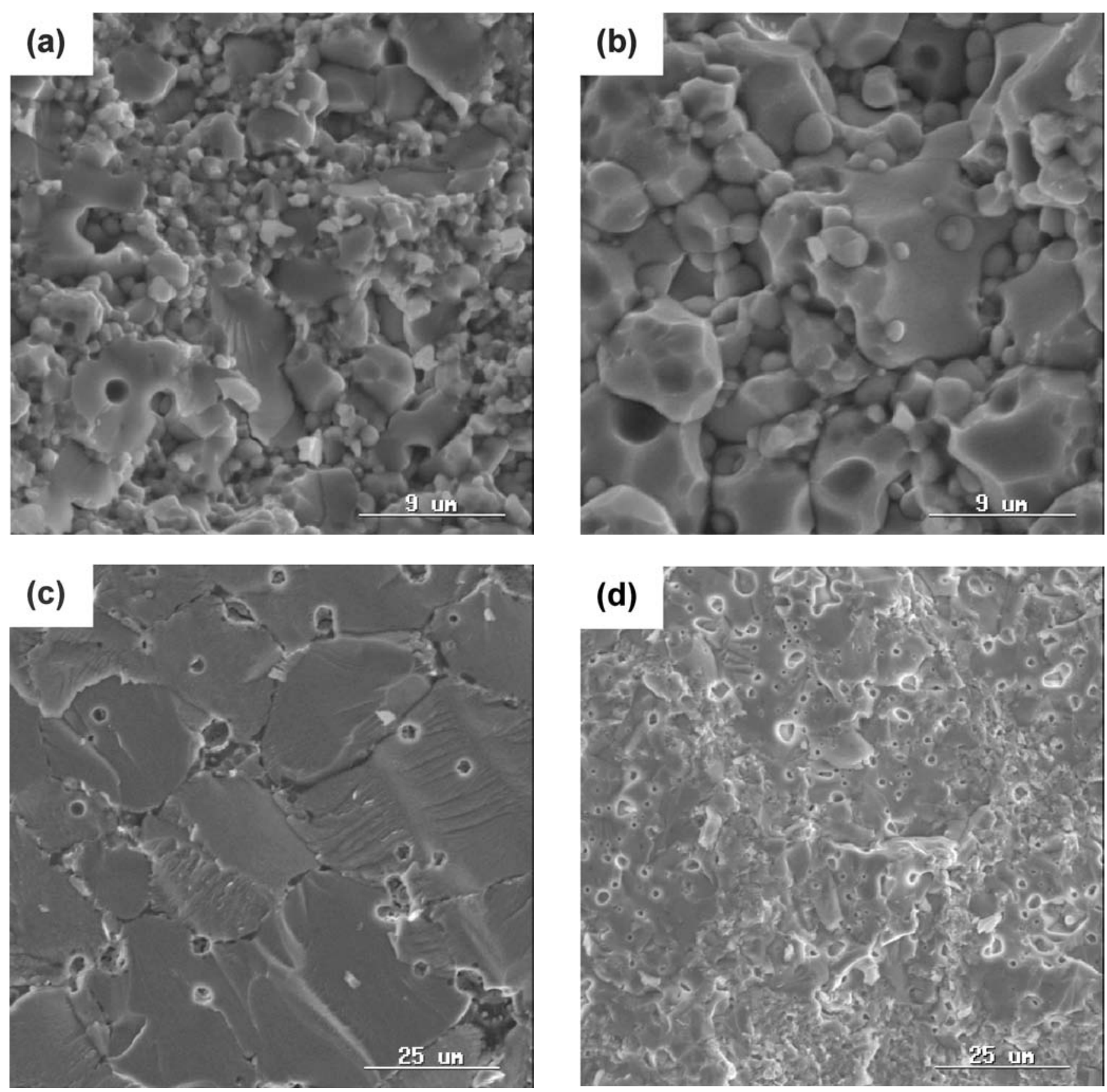

Figura 7: Micrografias de MEV das superfícies de fratura da amostra MCY sinterizada a: $1500{ }^{\circ} \mathrm{C}$ (a), $1600{ }^{\circ} \mathrm{C}$ (b) e $1700{ }^{\circ} \mathrm{C}$ (c); e da amostra M0 sinterizada a $1500{ }^{\circ} \mathrm{C}(\mathrm{d})$.

[Figure 7: SEM micrographs of fractured surfaces of the sample $\mathrm{MCY}$ sintered at: $1500{ }^{\circ} \mathrm{C}(\mathrm{a}), 1600^{\circ} \mathrm{C}(\mathrm{b})$, and $1700^{\circ} \mathrm{C}(\mathrm{c})$; and of the sample M0 sintered at $1500^{\circ} \mathrm{C}(\mathrm{d})$.]

maior valor médio de $378 \mathrm{MPa}$ foi observado na amostra de referência M0 sinterizada a $1700{ }^{\circ} \mathrm{C}$. Em geral, as amostras preparadas por meio de mistura de pós apresentaram maiores resistências quando sinterizadas a $1500{ }^{\circ} \mathrm{C}$. Nesta temperatura de sinterização, as amostras M3, MF, MY, CY e MCY apresentaram $\sim 300 \mathrm{MPa}$. Este valor de resistência à flexão é modesto comparado com os valores reportados em literatura para cerâmicas de Mg-PSZ que podem alcançar valores entre $\sim 500$ e $800 \mathrm{MPa}$ após tratamento térmico otimizado [1, 10]. Entretanto estes resultados geralmente são obtidos quando a sinterização é realizada em temperaturas elevadas (entre 1650 e $1850^{\circ} \mathrm{C}$ ), o resfriamento é realizado com taxas controladas e o tratamento térmico secundário é realizado por longos tempos em temperaturas entre $1100 \mathrm{e}$ $1450{ }^{\circ} \mathrm{C}[2,10]$, o que muitas vezes é difícil de ser posta em prática com fornos industriais convencionais. O valor de $\sim 380 \mathrm{MPa}$ observado na amostra M0, pó comercial de Mg-PSZ, sinterizado a $1700{ }^{\circ} \mathrm{C}$ e sem tratamento térmico secundário indica que em sinterização convencional o valor de resistência à flexão da cerâmica Mg-PSZ também é 
relativamente modesto. Este resultado está dentro da faixa de resistência à flexão observada por Hughan e Hannink [26] e indica que se for realizado resfriamento controlado na sinterização e aplicado o tratamento térmico de precipitação em condições otimizadas (temperatura e tempo) há a possibilidade de que tanto a amostra M0 quanto as amostras preparadas por meio de mistura de pós possam alcançar maiores valores de resistência mecânica.

$\mathrm{O}$ valor da resistência à flexão da amostra de referência M0 aumentou com o aumento da temperatura de sinterização, sendo mais pronunciado no intervalo entre 1500 e $1600{ }^{\circ} \mathrm{C}$ (Fig. 6). Esta variação coincidiu com a diminuição da fração da fase monoclínica de $26 \%$ para $4 \%$ nesta faixa de temperatura (Fig. 2a), mostrando a importância de se diminuir a fração de fase monoclínica para o aumento da resistência mecânica na amostra M0. As demais amostras apresentaram, em geral, comportamento oposto, tendo sido observada diminuição significativa da resistência com o aumento da temperatura de sinterização de 1500 para $1600{ }^{\circ} \mathrm{C}$, exceto as amostras Y3, YF e MC, que apresentaram valores baixos e próximos nestas temperaturas de sinterização. $\mathrm{O}$ aumento da temperatura de sinterização de 1600 para $1700{ }^{\circ} \mathrm{C}$ causou pequenas variações na resistência à flexão das amostras M3, MF, YF e C2, enquanto as amostras CF, CY e MCY apresentaram significativo aumento da resistência, cujos valores foram próximos aos obtidos em sinterização a 1500 ${ }^{\circ} \mathrm{C}$ (Fig. 6). Estes resultados não podem ser explicados apenas pela fração de fase monoclínica, que tendeu a diminuir com o aumento da temperatura de sinterização (Fig. 2). A diferença de comportamento da resistência em função da temperatura de sinterização parece estar associada ao modo de fratura das amostras. As amostras que apresentaram diminuição da resistência à flexão com o aumento da temperatura de sinterização apresentaram fratura predominantemente intergranular em toda a faixa de temperatura de sinterização estudada ( 1500 a $1700{ }^{\circ} \mathrm{C}$ ). Já as amostras que apresentaram um valor mínimo de resistência à flexão após sinterização a $1600{ }^{\circ} \mathrm{C}$ também apresentaram fratura predominantemente intergranular após sinterização a $1500{ }^{\circ} \mathrm{C}$ (Fig. 7a) e $1600{ }^{\circ} \mathrm{C}$ (Fig. 7b), mas passaram a apresentar fratura predominantemente transgranular a $1700{ }^{\circ} \mathrm{C}$ (Fig. 7c). Como comparação, a amostra de referência M0 apresentou fratura predominantemente transgranular em toda a faixa de temperatura de sinterização estudada $\left(1500\right.$ a $1700{ }^{\circ} \mathrm{C}$, Fig. 7d).

AFig. 8 apresenta os resultados de módulo de elasticidade, E, coeficiente de Poisson, v, dureza Vickers, HV, e tenacidade à fratura, $\mathrm{K}_{\mathrm{I}}$, de algumas amostras selecionadas sinterizadas a 1500 e $1700{ }^{\circ} \mathrm{C}$. A amostra MF sinterizada a $1700^{\circ} \mathrm{C}$ apresentou valores significativamente menores
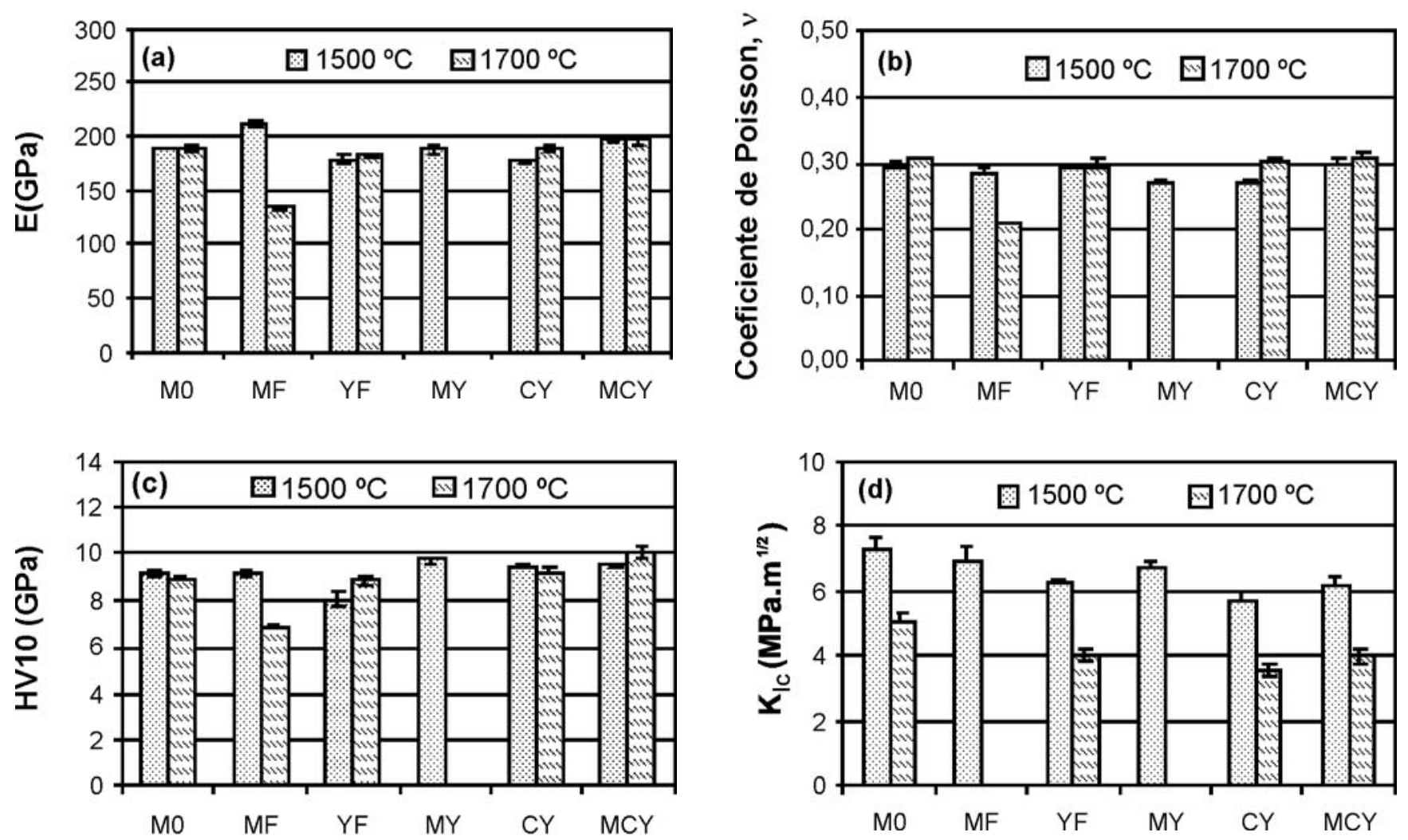

Figura 8: Módulo de Young, E (a), coeficiente de Poisson, v (b), dureza Vickers, HV (c), e tenacidade à fratura, $\mathrm{K}_{\mathrm{IC}}(\mathrm{d})$, de algumas amostras sinterizadas a 1500 e $1700^{\circ} \mathrm{C}$.

[Figure 8: Young's modulus, E (a), Poisson's ratio, v (b), Vickers hardness, $H V(c)$, and fracture toughness, $K_{I c}(d)$, of selected samples sintered at 1500 and $1700^{\circ} \mathrm{C}$.] 
de $\mathrm{E}, \mathrm{v}$ e $\mathrm{HV}$ em relação às demais amostras e apresentou formação de trincas curtas em apenas alguns vértices da indentação Vickers, o que impossibilitou a determinação de $\mathrm{K}_{\mathrm{IC}}$ pelo método IF. Excetuando esta amostra (MF sinterizada a $1700{ }^{\circ} \mathrm{C}$ ), os valores das propriedades E (Fig. 8a), v (Fig. 8b) e HV (Fig. 8c) foram próximos entre as diferentes amostras e, em geral, pouco influenciados pela temperatura de sinterização, sendo que os valores médios ( \pm desviopadrão) foram de (189 \pm 10$) \mathrm{GPa},(0,291 \pm 0,014)$ e $(9,2$ $\pm 0,5)$ GPa, respectivamente. Já os valores de $\mathrm{K}_{\mathrm{Ic}}$ (Fig. 8d) tiveram forte influência da temperatura de sinterização. As
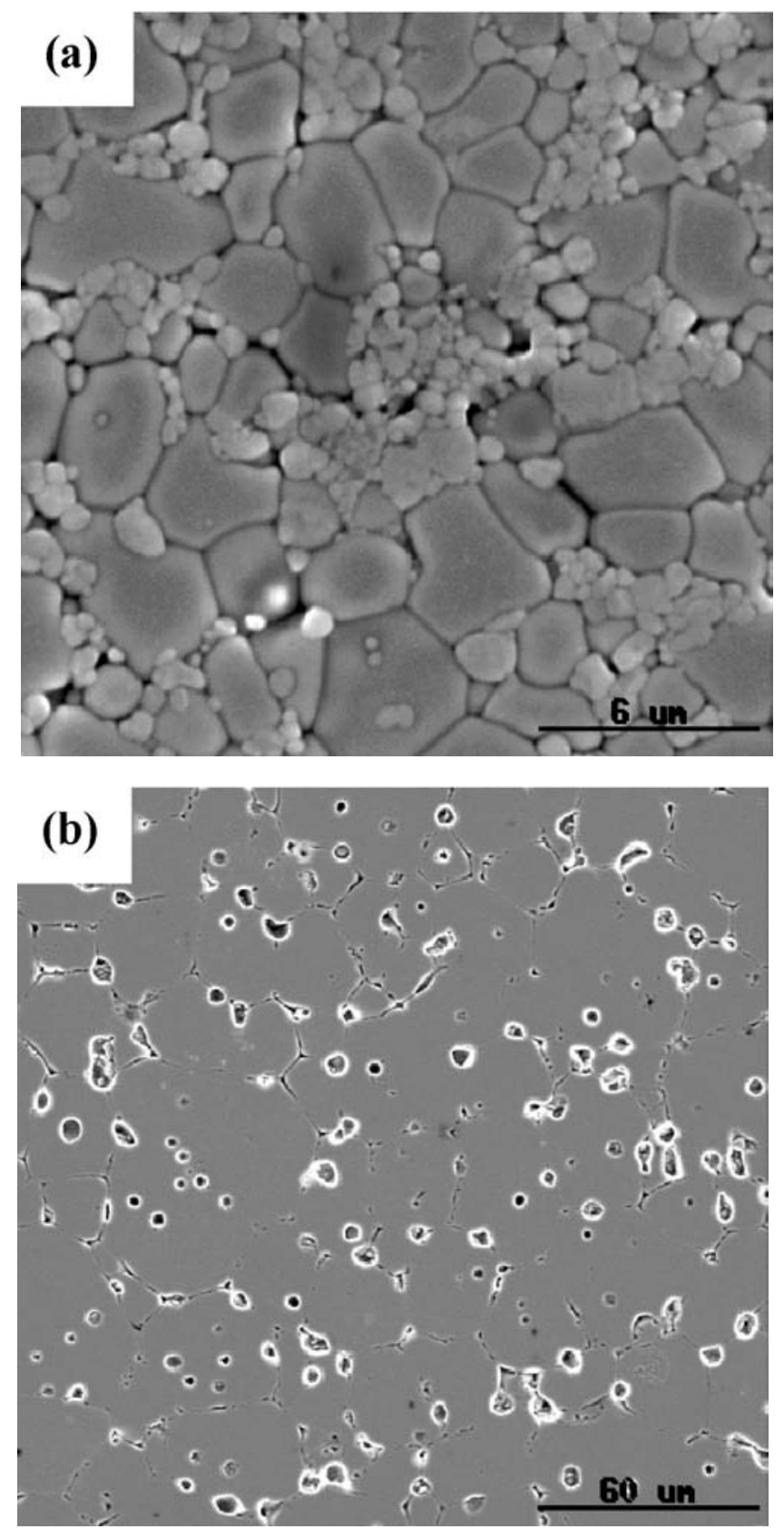

Figura 9: Micrografias de MEV de superfícies polidas e atacadas termicamente da amostra CY sinterizada a $1500{ }^{\circ} \mathrm{C}$ (a) e $1700{ }^{\circ} \mathrm{C}$ (b). [Figure 9: SEM micrographs of polished and thermally etched surfaces of the sample $\mathrm{CY}$ sintered at $1500^{\circ} \mathrm{C}$ (a) and $\left.1700^{\circ} \mathrm{C}(\mathrm{b}).\right]$
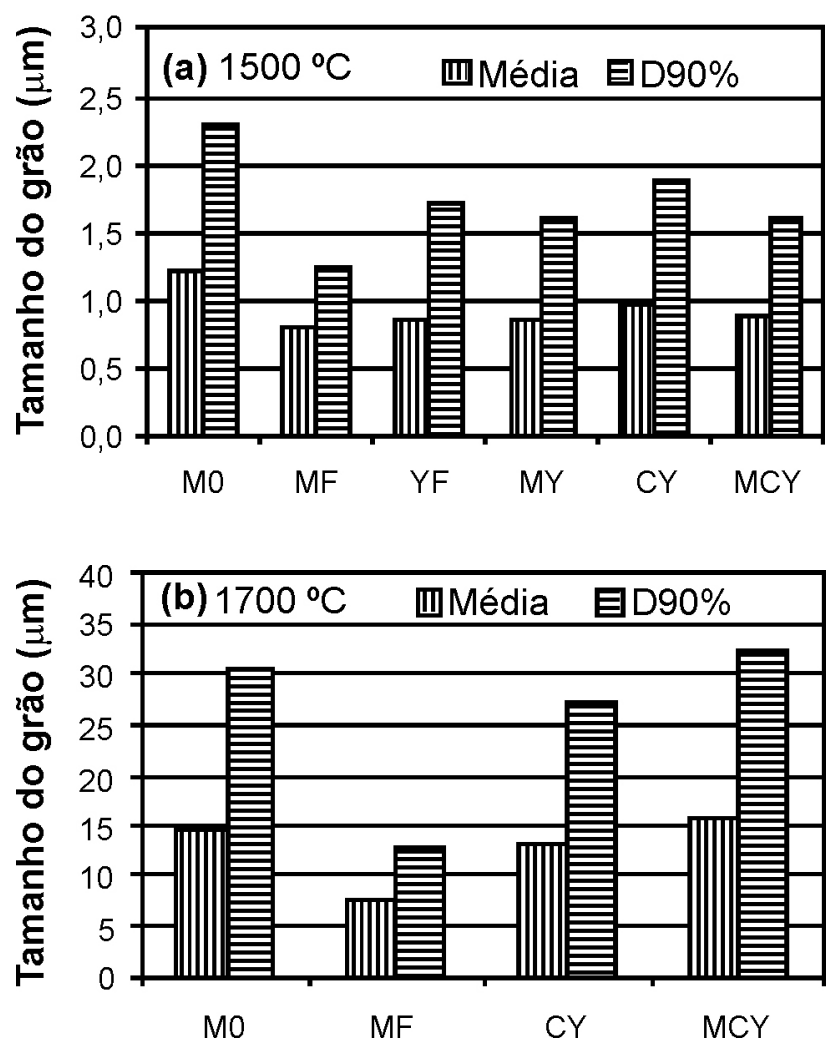

Figura 10: Tamanho de grão médio e tamanho de grão em $90 \%$ da curva de distribuição acumulada (D90\%) de algumas amostras sinterizadas a $1500{ }^{\circ} \mathrm{C}$ (a) e $1700{ }^{\circ} \mathrm{C}$ (b).

[Figure 10: Average grain size and grain size at $90 \%$ of cumulative distribution curve (D90\%) of selected samples sintered at $1500^{\circ} \mathrm{C}$ (a) and $1700^{\circ} \mathrm{C}($ b).]

amostras sinterizadas a $1500{ }^{\circ} \mathrm{C}$ apresentaram valores de $\mathrm{K}_{\mathrm{Ic}}$ variando entre 5,7 e 7,3 MPa.m ${ }^{1 / 2}$, sendo que as amostras MF e MY apresentaram valores próximos da amostra de referência, M0 ( 7 MPa.m $\left.{ }^{1 / 2}\right)$, enquanto as amostras YF, CY e MCY apresentaram valores um pouco menores $\left(\sim 6 \mathrm{MPa} \cdot \mathrm{m}^{1 / 2}\right)$. As amostras sinterizadas a $1700^{\circ} \mathrm{C}$ apresentaram valores de $\mathrm{K}_{\mathrm{Ic}}$ variando entre 3,5 e 5,0 MPa.m ${ }^{1 / 2}$, valores significativamente menores do que os das amostras sinterizadas a $1500{ }^{\circ} \mathrm{C}$, sendo que as amostras YF, CY e MCY apresentaram valores um pouco menores $\left(\sim 4 \mathrm{MPa} . \mathrm{m}^{1 / 2}\right)$ do que o da amostra de referência, M0 ( $\left.\sim 5 \mathrm{MPa} \cdot \mathrm{m}^{1 / 2}\right)$.

A diminuição da tenacidade à fratura com o aumento da temperatura de sinterização (Fig. 8d) parece estar relacionada à fração de fase tetragonal presente nas amostras. Como apresentado anteriormente, é de se esperar pelos diagramas de fase que as frações de fase tetragonal tenham sido maiores nas amostras sinterizadas a $1500^{\circ} \mathrm{C}$. As amostras sinterizadas a $1500{ }^{\circ} \mathrm{C}$ apresentaram distribuição bi-modal de tamanhos de grão (Fig. 9a), sendo que a literatura [9, 43-45] indica que os grãos menores são de fase tetragonal e os grãos maiores são de fase cúbica, pois a cinética de crescimento de grão da fase cúbica é significativamente maior do que a da fase tetragonal. Já as amostras sinterizadas a $1700{ }^{\circ} \mathrm{C}$ apresentaram somente grãos acentuadamente grandes (Fig. 
9b), indicando predominância de fase cúbica [45]. Não foi possível, entretanto, distinguir na microestrutura os grãos ou regiões dos grãos de fase monoclínica. $\mathrm{O}$ tamanho de grão médio, que foi de $\sim 1 \mu \mathrm{m}$ nas amostras sinterizadas a $1500{ }^{\circ} \mathrm{C}$ (Fig. 10a), aumentou cerca de uma ordem de grandeza nas amostras sinterizadas a $1700{ }^{\circ} \mathrm{C}$ (Fig. 10b). A diminuição da fração de fase tetragonal com o aumento da temperatura de sinterização parece ser, ao menos em parte, responsável pela diminuição de $\mathrm{K}_{\mathrm{Ic}}$ com o aumento da temperatura de sinterização (Fig. 8d). Conforme o trabalho de Zhang et al. [27], que estudaram uma cerâmica (Y,Mg)-PSZ sinterizada a $1700{ }^{\circ} \mathrm{C}$, maiores valores de $\mathrm{K}_{\mathrm{IC}}$ e resistência à flexão podem ser obtidos com longos tratamentos térmicos a $1100{ }^{\circ} \mathrm{C}$ para precipitação da fase tetragonal nos grãos de zircônia cúbica.

Os materiais cerâmicos, como o $\mathrm{ZrO}_{2}$, fraturam no modo frágil e a relação de Griffith-Irwin define a resistência mecânica:

$$
\sigma_{\mathrm{f}}=\mathrm{K}_{\mathrm{Ic}} /\left(\mathrm{Yc}^{1 / 2}\right)
$$

onde, $\sigma_{\mathrm{f}}$ é a tensão de fratura, $\mathrm{K}_{\mathrm{Ic}}$ é a tenacidade à fratura, Y é o fator de forma e c é o tamanho do defeito crítico. Por esta relação observa-se que a resistência varia diretamente com $K_{\mathrm{Ic}}$ e inversamente com $V_{c}$. Assim, a diminuição da resistência à flexão com o aumento da temperatura de sinterização observada em algumas amostras (Fig. 6) parece estar relacionada, ao menos em parte, à diminuição da tenacidade à fratura (Fig. 8d). No caso das amostras que apresentaram valor mínimo de resistência à flexão após sinterização a $1600{ }^{\circ} \mathrm{C}$ (CF, CY e MCY, Fig. 6), a relação de Griffith-Irwin sugere que o tamanho do defeito limitador da resistência, c, foi menor nas amostras sinterizadas a $1700^{\circ} \mathrm{C} \mathrm{em}$ comparação às mesmas sinterizadas a $1500{ }^{\circ} \mathrm{C}$, uma vez que ocorreu diminuição do valor de $\mathrm{K}_{\mathrm{IC}}$ entre estas duas temperaturas de sinterização (Fig. 8d). Esta análise coincide com a mudança no modo de fratura de predominantemente intergranular para transgranular observada nestas amostras (Figs. 7a a 7c). Como apresentado anteriormente, a amostra de referência M0 apresentou modo de fratura predominantemente transgranular em toda a faixa de temperatura de sinterização estudada (1500 a $1700^{\circ} \mathrm{C}$, Fig. $7 \mathrm{~d}$ ), mas a resistência à flexão só aumentou significativamente a partir de $1600{ }^{\circ} \mathrm{C}$ (Fig. 6). Segundo a relação de Griffith-Irwin (Eq. G), este aumento deve ter sido decorrente de diminuição significativa do tamanho do defeito crítico, pois a tenacidade à fratura desta amostra também diminuiu com o aumento da temperatura de sinterização (Fig. 8d).

Na temperatura de sinterização de $1500{ }^{\circ} \mathrm{C}$, as amostras preparadas por meio de mistura de pós apresentaram valores de resistência à flexão, em geral, significativamente maiores do que o da amostra M0 (Fig. 6), sugerindo que nessas amostras ocorreu a atuação de um mecanismo de tenacificação adicional, além do possível mecanismo tenacificador decorrente da fase tetragonal. Estas amostras apresentaram predominância de fratura intergranular após sinterização a $1500^{\circ} \mathrm{C}$ (Fig. 7a), o que sugere a ocorrência do mecanismo de microtrincamento, que causou a propagação da trinca possivelmente pelas interfaces entre os grãos das diferentes fases polimórficas da zircônia [46]. As frações relativamente elevadas da fase monoclínica nas amostras sinterizadas a $1500{ }^{\circ} \mathrm{C}$ (Fig. 2) podem ter favorecido a ocorrência de fratura intergranular, decorrente das tensões internas geradas pela expansão volumétrica desta fase devido à desestabilização das fases de alta temperatura durante o resfriamento no ciclo de sinterização. Entretanto, apenas a presença da fase monoclínica não explica a ocorrência de fratura intergranular, pois a amostra de referência M0 também apresentou significativa fração desta fase após sinterização a $1500{ }^{\circ} \mathrm{C}$ (Fig. 2a), mas o seu modo de fratura foi predominantemente transgranular (Fig. 7d). O tamanho de grão é um fator importante na determinação do modo de fratura, pois os grãos finos tendem a fraturar intergranularmente e os grãos grandes transgranularmente [46]. A amostra M0 apresentou tamanho de grão médio maior e distribuição de tamanho de grão mais larga (conforme valor de tamanho em $90 \%$ da curva acumulada, D90\%) do que as amostras preparadas por meio de mistura de pós (Fig. 10a). As diferenças, entretanto, parecem ser pequenas para justificar as diferenças no modo de fratura. Vale notar que as amostras preparadas por meio de mistura de pós continuaram a apresentar fratura intergranular após sinterização a $1600{ }^{\circ} \mathrm{C}$ (Fig. 7b), mesmo após significativo crescimento de grão (comparar micrografias das Figs. 7a e 7b). Os resultados, assim, sugerem que a ocorrência de fratura intergranular e, portanto, do mecanismo de microtrincamento foi causado por um fator adicional nas amostras preparadas por meio de mistura de pós.

O comportamento de diminuição da resistência à flexão com o aumento da temperatura de sinterização observado nas amostras preparadas por meio de mistura de pós pode estar relacionado com o teor de $\mathrm{SiO}_{2}$ relativamente alto $(0,49 \%)$ do pó de zircônia monoclínica de partida utilizado. Garvie et al. [10] observaram que amostras de Mg-PSZ preparadas a partir de pó de zircônia monoclínica com teor de sílica acima de $0,03 \%$ em peso apresentaram severo trincamento após a sinterização a $1725^{\circ} \mathrm{C}$ e/ou após tratamento térmico secundário, o que diminuiu a resistência à flexão e aumentou o seu desvio-padrão. A presença de microtrincas superficiais (Fig. 4) e os valores elevados de porosidade aparente nas amostras sinterizadas acima de $1500{ }^{\circ} \mathrm{C}$ (Fig. 3b) estão em acordo com estas observações [10]. A presença da impureza de $\mathrm{SiO}_{2}$ nas cerâmicas de zircônia causa a formação de uma fase secundária de silicato com os aditivos nos contornos de grão, o que causa a diminuição da fração de aditivo em solução sólida nos grãos de $\mathrm{ZrO}_{2}$ e a degradação das propriedades mecânicas [47]. Assim, possivelmente ocorreu a formação de fases secundárias contendo $\mathrm{SiO}_{2}$ nos contornos de grão das amostras preparadas por meio de mistura de pós, embora não tenham sido detectadas nas análises por MEV e DRX. A não detecção por estas técnicas indica que as fases secundárias não eram cristalinas e/ou estavam presentes em baixas frações. A possível presença de fases secundárias nos contornos de grão parece justificar a ocorrência de fratura intergranular nas amostras preparadas por meio de mistura 
de pós. Assim, propõe-se que a atuação do mecanismo de microtrincamento, causado pelas fases secundárias ricas em $\mathrm{SiO}_{2}$ nos contornos de grão, foi responsável pelo modo de fratura intergranular nestas amostras. A atuação deste mecanismo parece ter possibilitado um maior armazenamento de energia elástica pelo corpo-de-prova durante o ensaio de flexão biaxial, o que resultou em maiores valores de resistência à flexão nas amostras preparadas por meio de mistura de pós e sinterizadas a $1500^{\circ} \mathrm{C}$, em relação à amostra M0 sinterizada na mesma temperatura (Fig. 6).

A causa da diminuição da resistência à flexão nas amostras preparadas por meio de mistura de pós e sinterizadas a $1600{ }^{\circ} \mathrm{C}$ (Fig. 6) parece estar relacionada à ocorrência de microtrincamento espontâneo durante o resfriamento no ciclo de sinterização, o que resultou no aumento do tamanho de defeito crítico que limitou a resistência [48]. O aumento da porosidade aparente em várias amostras sinterizadas a 1600 ${ }^{\circ} \mathrm{C}$ (Fig. 3) indica que ocorreu microtrincamento espontâneo nestas amostras. A causa da geração espontânea de trincas não pode ser correlacionada diretamente à fase monoclínica, pois as amostras, em geral, apresentaram diminuição da fração desta fase com o aumento da temperatura de sinterização (Fig. 2). Possivelmente o microtrincamento espontâneo foi causado pelo engrossamento microestrutural (Fig. 7b), pois, embora a expansão térmica total associada à formação da fase monoclínica possivelmente tenha sido menor do que a $1500{ }^{\circ} \mathrm{C}$, a tensão gerada ao redor dos grãos grandes pode ter sido maior a $1600{ }^{\circ} \mathrm{C}$, similar ao que ocorre em cerâmicas com anisotropia de expansão térmica, como a alumina, que apresenta geração espontânea de trincas acima de um determinado tamanho de grão crítico [46]. O modo de fratura predominantemente intergranular nas amostras sinterizadas a $1600{ }^{\circ} \mathrm{C}$ (Fig. 7b) indica que as trincas geradas espontaneamente foram dotipointergranulardevidoàpossível presença de fases secundárias ricas em $\mathrm{SiO}_{2}$ nos contornos de grão. Embora a atuação destas fases secundárias pareça ambígua, ora aumentando a resistência, no caso das amostras sinterizadas a $1500{ }^{\circ} \mathrm{C}$, e ora diminuindo esta propriedade, no caso das amostras sinterizadas a $1600{ }^{\circ} \mathrm{C}$, este efeito é típico de materiais cerâmicos que apresentam tensões residuais localizadas [48]. Quando o material é produzido com grãos abaixo do tamanho crítico para ocorrência de microtrincamento espontâneo, a geração de microtrincas secundárias, induzida pelo campo de tensão na ponta de uma trinca "principal" ou em propagação, diminui a tensão na ponta dessa trinca, resultando em uma "proteção" da ponta da trinca (crack tip shielding) [48]. Isto exige um aumento da tensão externa aplicada ao corpo para a propagação da trinca (fratura), o que resulta em aumento da resistência mecânica do material. Por outro lado, quando a cerâmica é produzida com microtrincas geradas espontaneamente, estas microtrincas podem atuar como iniciadores da fratura, resultando em diminuição da resistência [48]. Isto mostra a importância de se manter pequeno os grãos da zircônia produzida com impureza de sílica, que é alcançado com baixa temperatura de sinterização $\left(1500^{\circ} \mathrm{C}\right)$.

No caso das amostras que apresentaram valor mínimo de resistência à flexão após sinterização a $1600{ }^{\circ} \mathrm{C}$ (CF, CY e MCY, Fig. 6), a causa do aumento da resistência após sinterização a $1700{ }^{\circ} \mathrm{C}$ não está clara. Essas amostras apresentaram elevados valores de porosidade aparente, como as demais amostras preparadas por meio de mistura de pós, indicando a ocorrência de microtrincamento espontâneo. Especula-se que nessas amostras, as trincas espontâneas tiveram pouca influência na propagação da fratura durante o ensaio de flexão, uma vez que o modo de fratura foi predominantemente transgranular (Fig. 7c). A mudança de fratura intergranular das amostras sinterizadas a $1600{ }^{\circ} \mathrm{C}$ (Fig. 7b) para transgranular a $1700{ }^{\circ} \mathrm{C}$ (Fig. 7c) pode estar relacionada à diminuição de fração de fase monoclínica (Fig. 2) e o significativo crescimento de grão que ocorreu nestas amostras. A Fig. 10b mostra que as amostras CY e

Tabela IV - Características das amostras M0, MF, MY, CY e MCY. Entre parênteses são apresentados os valores relativos em relação aos resultados da amostra M0.

[Table IV - Data of samples MO, MF, MY, CY, and MCY. Relative values in relation to the results of sample MO are showing in parenthesis.]

\begin{tabular}{cccccc}
\hline Característica & $\mathrm{M} 0$ & $\mathrm{MF}$ & $\mathrm{MY}$ & $\mathrm{CY}$ & $\mathrm{MCY}$ \\
\hline $\begin{array}{c}\text { Teores de aditivos } \\
\text { (\% em peso) }\end{array}$ & $3,2 \% \mathrm{MgO}$ & $3,9 \% \mathrm{MgO}$ & $1,8 \% \mathrm{MgO}-$ & $2,5 \% \mathrm{CaO}-$ & $1,2 \% \mathrm{MgO}-1,7 \%$ \\
& & & $5,9 \% \mathrm{Y}_{2} \mathrm{O}_{3}$ & $5,9 \% \mathrm{Y}_{2} \mathrm{O}_{3}$ & $\mathrm{CaO}-4,0 \% \mathrm{Y}_{2} \mathrm{O}_{3}$ \\
Temperatura de sinterização $\left({ }^{\circ} \mathrm{C}\right)$ & 1700 & 1500 & 1500 & 1500 & 1500 \\
Fração de fase monoclínica & $4 \%$ & $54 \%$ & $31 \%$ & $21 \%$ & $27 \%$ \\
Densidade aparente $\left(\mathrm{g} / \mathrm{cm}^{3}\right)$ & 5,50 & 5,69 & 5,78 & 5,70 & 5,69 \\
Porosidade aparente $(\%)$ & 0,23 & 0,22 & 0,22 & 0,10 & 0,07 \\
Tamanho de grão $(\mu \mathrm{m})$ & 14,5 & 0,80 & 0,83 & 0,96 & 0,88 \\
Rugosidade Ra $(\mu \mathrm{m})$ & 0,07 & 0,05 & 0,06 & 0,05 & 0,05 \\
Resistência à flexão $(\mathrm{MPa})$ & 378 & $309(0,82)$ & $294(0,78)$ & $305(0,81)$ & $287(0,76)$ \\
Dureza Vickers $(\mathrm{GPa})$ & 8,94 & $9,16(1,02)$ & $9,74(1,09)$ & $9,42(1,05)$ & $9,50(1,06)$ \\
Tenacidade à fratura $\left(\mathrm{MPa} \cdot \mathrm{m}^{1 / 2}\right)$ & 5,04 & $6,93(1,37)$ & $6,68(1,32)$ & $5,72(1,13)$ & $6,20(1,23)$ \\
\hline
\end{tabular}


MCY sinterizadas a $1700{ }^{\circ} \mathrm{C}$ apresentaram tamanhos de grão médios significativamente maiores e distribuições de tamanho de grão mais largas (D90\%) do que a amostra MF, que apresentou fratura predominantemente intergranular nesta temperatura de sinterização.

Em suma, os maiores valores de resistência à flexão biaxial observados nas amostras MY, CY e MCY sinterizadas a $1500{ }^{\circ} \mathrm{C}$ (Fig. 6) parecem estar associados a uma fração relativamente baixa de fase monoclínica (até $\sim 30 \%$, Fig. 2d) e, principalmente, ao tamanho de grão relativamente pequeno (até $\sim 1 \mu \mathrm{m}$, Fig. 10a). A importância do tamanho de grão pequeno também é manifestada nas amostras M3 e MF, pois apresentaram valores de resistência mecânica relativamente altos a $1500{ }^{\circ} \mathrm{C}$ (Fig. 6), apesar de conterem $\sim 55 \%$ de fase monoclínica (Fig. 2a).

Em geral, a amostra M0 apresentou os melhores resultados quando sinterizada a $1700^{\circ} \mathrm{C}$, exceto a tenacidade à fratura. Tomando-se como base estes resultados, as amostras que apresentaram resultados dentro das metas estabelecidas foram (\% em mol): MF (11,0\% de MgO), MY (5,5\% MgO$\left.3,2 \% \mathrm{Y}_{2} \mathrm{O}_{3}\right)$, CY $\left(5,5 \% \mathrm{CaO}-3,2 \% \mathrm{Y}_{2} \mathrm{O}_{3}\right)$ e $\mathrm{MCY}(3,7 \%$ MgO-3,7\% CaO-2,1\% $\mathrm{Y}_{2} \mathrm{O}_{3}$ ), sinterizadas a $1500{ }^{\circ} \mathrm{C}$, cujos resultados estão compilados na Tabela IV.

Observa-se na Tabela IV que apenas os resultados de resistência à flexão ficaram próximos ao limite inferior (cerca de $80 \%$ ) da meta proposta. Entretanto, estes resultados de resistência são significativamente superiores ao da amostra M0 sinterizada a $1500{ }^{\circ} \mathrm{C}$ (Fig. 6). Assim, os pós com composições de aditivos MF, MY, CY e MCY apresentam a vantagem de poderem ser sinterizados em uma temperatura menor $\left(1500{ }^{\circ} \mathrm{C}\right)$ do que o pó de referência, M0, para a obtenção de cerâmicas de zircônia parcialmente estabilizada compropriedades mecânicas aceitáveis. Os resultados também mostraram que, em geral, as composições mistas de aditivos alcançaram maiores êxitos, principalmente as contendo $\mathrm{Y}_{2} \mathrm{O}_{3}$. Uma das composições da Tabela IV foi testada para a produção de uma polia com diâmetro de $\sim 150 \mathrm{~mm}$ em escala piloto utilizando equipamentos de processamento industriais. A sinterização foi realizada a $\sim 1500{ }^{\circ} \mathrm{C}$ em forno industrial a gás e as superfícies foram usinadas em retificadora cilíndrica. As peças foram aplicadas em uma indústria de trefilação de fios metálicos especiais e o desempenho foi similar às peças produzidas com o pó de referência M0 sinterizadas a $\sim 1670$ ${ }^{\circ} \mathrm{C}$, tendo apresentado vida útil acima de 1 ano. Neste caso, os principais parâmetros de projeto foram a estabilidade do material, a baixa rugosidade superficial e a resistência ao desgaste, e não a resistência mecânica, o que possibilitou aplicação da formulação de aditivos desenvolvida (Tabela IV). A rota de processamento desenvolvida neste trabalho foi implantada na empresa Engecer e lotes de peças estão sendo regularmente produzidos com as novas formulações de PSZ.

\section{CONCLUSÕES}

$\mathrm{O}$ aditivo mais efetivo para estabilização das fases de zircônia de alta temperatura (tetragonal e cúbica) foi o $\mathrm{Y}_{2} \mathrm{O}_{3}$, seguido pelos aditivos $\mathrm{CaO}$ e $\mathrm{MgO}$. A estabilização destas fases foi favorecida pelo aumento do teor dos aditivos e aumento da temperatura de sinterização. Frações elavadas de aditivos foram necessárias para a estabilização das fases de alta temperatura, provavelmente devido à presença de partículas grandes (até $\sim 10 \mu \mathrm{m}$ ) no pó de $\mathrm{ZrO}_{2}$ monoclínico de partida.

As amostras de zircônia parcialmente estabilizada preparadas por meio de mistura de pós apresentaram, em geral, melhores propriedades (densidade aparente, porosidade aparente, rugosidade $\mathrm{Ra}$ após usinagem em retificadora, resistência à flexão biaxial e tenacidade à fratura) quando sinterizadas a $1500{ }^{\circ} \mathrm{C}$ com elevadas frações de aditivos. Os maiores valores de resistência à flexão alcançados foram, entretanto, modestos ( $\sim 300 \mathrm{MPa})$. As propriedades de módulo de elasticidade, coeficiente de Poisson e dureza Vickers foram pouco influenciados pela temperatura de sinterização na faixa de 1500 e $1700{ }^{\circ} \mathrm{C}$.

As amostras preparadas por meio de mistura de pós apresentaram, em geral, maiores valores de resistência à flexão do que a amostra de referência (pré-aditivada), quando sinterizadas a $1500{ }^{\circ} \mathrm{C}$, possivelmente devido à atuação do mecanismo de tenacificação por microtrincamento. O aumento da temperatura de sinterização causou, em geral, diminuição da resistência à flexão, possivelmente devido à ocorrência de microtrincamento espontâneo. Ambos comportamentos foram influenciados pelas tensões internas, geradas pela formação da fase monoclínica, e pela presença de $\sim 0,5 \%$ de $\mathrm{SiO}_{2}$ no pó de zircônia monoclínica de partida, que enfraqueceu o contorno de grão e propiciou a fratura intergranular. O tamanho de grão, entretanto, definiu os dois comportamentos: abaixo do tamanho crítico, a formação das microtrincas foi induzida pela ação do campo de tensão na ponta da trinca, durante o carregamento no ensaio mecânico, enquanto acima do tamanho crítico, as microtrincas foram geradas espontaneamente pelas tensões térmicas, durante o resfriamento no ciclo de sinterização, aumentando o tamanho do defeito crítico.

Os resultados mostraram queépossível produzircerâmicas de zircônia parcialmente estabilizada com propriedades mecânicas aceitáveis e desempenho satisfatório na usinagem em retificadora cilíndrica por meio de mistura mecânica de pós utilizando um pó de zircônia monoclínica de baixo custo com $\sim 0,5 \%$ de sílica. Para tanto é necessário utilizar maiores teores de aditivos do que os usualmente empregados nos pós comerciais pré-aditivados, para estabilização das fases tetragonal e/ou cúbica, e manter o tamanho de grão pequeno, que é alcançado com baixa temperatura de sinterização (1500 ${ }^{\circ} \mathrm{C}$ ). Em geral, as composições de aditivos multicomponentes do sistema $\mathrm{MgO}-\mathrm{Y}_{2} \mathrm{O}_{3}-\mathrm{CaO}$, contendo $\mathrm{Y}_{2} \mathrm{O}_{3}$, apresentaram os melhores resultados.

As formulações de aditivos que alcançaram as metas propostas (rugosidade $\mathrm{Ra}<0,1 \mu \mathrm{m}$ após usinagem e mínimo de $\sim 80 \%$ dos valores de resistência à flexão, dureza e tenacidade à fratura de uma cerâmica de Mg-PSZ preparada com pó comercial) foram: 11,0\% MgO; 5,5\% MgO-3,2\% $\mathrm{Y}_{2} \mathrm{O}_{3} ; 5,5 \% \mathrm{CaO}-3,2 \% \mathrm{Y}_{2} \mathrm{O}_{3}$; e 3,7\% MgO-3,7\% CaO-2,1\% $\mathrm{Y}_{2} \mathrm{O}_{3}$ (\% em mol). 


\section{REFERÊNCIAS}

[1] R. Stevens, in Engineered Materials Handbook, Vol. 4, Ceramics and Glasses. Ed. S. J. Schneider, Jr., ASM International, EUA (1991) p. 775.

[2] I. Birkby, R.Stevens, Key Eng. Mater. 122-124 (1996) 527.

[3] E. C. Subbarao, in Science and Technology of Zirconia, Advances in Ceramics, vol. 3, Eds. A. H. Heuer, L. W. Hobbs, The American Ceramic Society, Columbus (1981) p. 1.

[4] H. L. Johns, Tetragonally stabilized zirconia ceramic, US Patent 4.035.191, 1977.

[5] D. L. Guile, Stabilized zirconia bodies of improved toughness, US Payent 4.659.680, 1987.

[6] T. Quadir, Low temperature sintering of yttria stabilized zirconia with lanthana borate additions, US Patent 4.764.491, 1988.

[7] T. Quadir, Stabilized zirconia, US Patent 5.658.837, 1997.

[8] S. Lawson, J. Eur. Ceram. Soc. 15 (1995) 485.

[9] J. Chevalier, Biomaterials 27 (2006) 535.

[10] R. C. Garvie, R. H. J. Hannink, N. A. McKinnon, Partially stabilized zirconia ceramics, US Patent 4.279.655, 1981.

[11] M. D. Stuart, W. H. Ta, High-strength magnesia partially stabilized zirconia, US Patent 6.723.672 B1, 2004.

[12] P. M. Kelly, L. R. F. Rose, Progress in Materials Science 47 (2002) 463.

[13] H. Miyazaki, J. Nakano, T. Kimura, T. Goto, J. Ceram. Soc. Japan 112, 5 (2004) S881.

[14] S. R. Choi, D. Zhu, R. A. Miller, J. Am. Ceram. Soc. 88, 10 (2005) 2859.

[15] R. H. J. Hannink, P. M. Kelly, B. C. Muddle, J. Am. Ceram. Soc. 83, 3 (2000) 461.

[16] B. Basu, Int. Mat. Reviews 50, 4 (2005) 239.

[17] H. N. Yoshimura, P. F. Cesar, W. G. Miranda Jr., C. C. Gonzaga, C. Y. Okdada, H. Goldenstein, J. Am. Ceram. Soc. 88, 6 (2005) 1680.

[18] M. L. Mecartney, J. Am. Ceram. Soc. 70, 1 (1987) 54.

[19] G. W. Dransmann, R. W. Steinbrech, A. Pajares, F.

Guiberteau, A. Dominguez-Rodriguez, A. H. Heuer, J. Am. Ceram. Soc. 77, 5 (1994) 1194.

[20] M. M. Bucko, W. Pyda, J. Mater. Sci. 40 (2005) 5191.

[21] G. Fargas, D. Casellas, L. Llanes, M. Anglada, J. Eur. Ceram. Soc. 23 (2003) 107.

[22] H. Kondo, T. Sekino, T. Kusunose, T. Nakayama, Y. Yamamoto, M. Wada, T. Adachi, K. Niihara, J. Am. Ceram. Soc. 86, 3 (2002) 523.

[23] T.-J. Chung, H. Song, G.-H. Kim, D.-Y. Kim, J. Am. Ceram. Soc. 80, 10 (1997) 2607.

[24] H. Liang, T. E. Fischer, M. Nauer, C. Carry, J. Am.
Ceram. Soc. 76, 2 (1993) 325.

[25] R. H. J. Hannink, C. J. Howard, E. H. Kisi, M. V. Swain, J. Am. Ceram. Soc. 77, 2 (1994) 571.

[26] R. R. Hughan, R. H. J. Hannink, J. Am. Ceram. Soc. 69, 7 (1986) 556.

[27] Q. Zhang, H. Z. Wu, Y. R. Chen, W. X. Liu, Q. M. Yuan, J. Eur. Ceram. Soc. 18 (1998) 647.

[28] P. Ramaswamy, B. H. Narayan, S. Vynatheya, Ceram. Int. 22 (1996) 287.

[29] J. B. Wachtman, Mechanical properties of ceramics, John Wiley \& Sons, New York (1996) 391.

[30] R. J. Hill, B. E. Reichert, J. Am. Ceram. Soc. 73, 10 (1990) 2822.

[31] F. L. Cumbrera, F. Sanchez-Bajo, R. Fernández, L Llanes, J. Eur. Ceram. Soc. 18 (1998) 2247.

[32] W. J. Buykx, M. V. Swain, in Science and Technology of Zirconia II, Advances in Ceramics, vol. 12, Ed. N. Claussen, M. Rühle, A. H. Heuer, The American Ceramic Society, Columbus (1983) p. 518.

[33] M. Matsui, T. Soma, I. Oda, in Science and Technology of Zirconia II, Advances in Ceramics, vol. 12, Ed. N. Claussen, M. Rühle, A. H. Heuer, The American Ceramic Society, Columbus (1983) p. 371.

[34] F. F. Lange, J. Am. Ceram. Soc. 72, 1 (1989) 3.

[35] A. G. Evans, E. A. Charles, J. Am. Ceram. Soc. 59, 7-8 (1976) 371.

[36] K. Niihara, R. Morena, D. P. H. Hasselman, J. Mater. Sci. Lett. 1 (1982) 13.

[37] G. R. Anstis, P. Chantikul, B. R. Lawn, D. B. Marshall, J. Am. Ceram. Soc. 64, 9 (1981) 533.

[38] K. M. Liang, G. Orange, G. Fantozzi, J. Mater. Sci. 25 (1990) 207.

[39] U. Martin, H. Boysen, F. Frey, Acta Cryst. B49 (1993) 403.

[40] M. Yashima, S. Sasaki, M. Kakihana, Y. Yamaguchi, H. Arashi, M. Yoshimura, Acta Cryst. B 50 (1994) 663.

[41] C. J. Howard, E. H. Kisi, R. B. Roberts, R. J. Hill, J. Am. Ceram. Soc. 73, 10 (1990) 2828.

[42] A. P. Bechepeche, O. Treu Jr, E. Longo, C. O. PaivaSantos, J. A. Varela, J. Mater. Sci. 34 (1999) 2751.

[43] W. Z. Zhu, Ceram. Int. 24 (1998) 35.

[44] J. Chevalier, S. Deville, E. Münch, R. Jullian, F. Lair, Biomaterials 25 (2004) 5539.

[45] Y. Kan, G. Zhang, P. Wang, O. V. der Biest, J. Vleugels, J. Eur. Ceram. Soc. 26, 16 (2006) 3607.

[46] R. W. Rice, Mechanical properties of ceramics and composites: grain and particle effects, Marcel Dekker, New York (2000) 43.

[47] J. Drennan, R. H. J. Hannink, J. Am. Ceram. Soc. 69, 7 (1986) 541.

[48] D. J. Green, An introduction to the mechanical properties of ceramics, Cambridge University Press, Cambridge (1998) 258. (Rec. 01/04/2005, Rev. 27/09/2006/ Ac. 16/02/2007) 